\title{
El florecimiento humano como mirador iconoclasta ante la mundialización de la pobreza
}

\author{
Luis Arizmendi
}

Comenzando por dar cuenta del cinismo como identidad histórica de nuestro tiempo, este ensayo presenta una conceptualización global pero sintética del triple fundamento que origina la mundialización de la pobreza -esto es, la configuración neoliberal, la derrota de los monopolios defensivos que detentaron los Estados del Segundo y Tercer Mundos y la dinámica con la que la revolución tecnológica en curso apuntala el poder planetario- para, frente a este escenario, realizar un balance panorámico desde el cual puedan valorarse los decisivos alcances de Ampliar la mirada -la obra con la que Julio Boltvinik realiza su mayor contribución al debate internacional de frontera sobre la pobreza-, que tiene en los principios de la totalidad, la transdisciplinariedad, la economía moral y la autodeterminación nacional, la plataforma de toda una concepción iconoclasta que permite pensar la pobreza en clave de valor de uso.

PALABRAS CLAVE: mundialización, pobreza, cinismo, florecimiento humano

By presenting cynicism as an historical identity of present times, this paper conceptualizes, in a global yet synthetic manner, the triple foundation that originates the globalization of poverty - that is: the neoliberal configuration, the defeat of the defensive monopolies held by the States of the Second and Third Worlds and the dynamic with which the technological revolution strengthens global power- in order to realize a comprehensive assessment from which we can evaluate the decisive contributions of Julio Boltvinik's Ampliar la mirada, his biggest contribution to the international debate about poverty. This work is an iconoclastic view, build upon the principles of totality, transdisciplinarian thought, moral economy and national self-determination, that allows the conceptualization of poverty as use-value.

KEY WORDS: globalization, poverty, cynicism, human flourishing

LUIS ARIZMENDI: Centro de Investigaciones Económicas, Administrativas y Sociales, Instituto Politécnico Nacional, México-Distrito Federal arizmendi_luis@hotmail.com

Desacatos, núm. 23, enero-abril 2007, pp. 101-124.

Recepción: 22 de septiembre de 2006 / Aceptación: 24 de octubre de 2006 
A diferencia de otros campos, donde los fenómenos estudiados y medidos son moralmente neutros [...], en el caso de la pobreza interviene inevitablemente una dimensión moral [...] Al establecer el umbral de la pobreza, las personas y las instituciones se retratan de cuerpo entero [...] Cuando el Banco Mundial define un dólar por persona al día como umbral o línea de pobreza está mostrando su concepción del ser humano al reducirlo a la categoría de animal no humano, ya que, en efecto, ese ingreso alcanzaría, en el mejor de los casos, para mal alimentar a una persona, quedando todas las demás necesidades insatisfechas. Así, al sostener implícita, pero brutalmente, que los seres humanos sólo tienen derecho a la alimentación, el Banco Mundial niega todos los demás derechos sociales. Algo similar, aunque no tan extremo, podemos decir de la CEPAL y del gobierno de México. Muchos economistas (y no economistas), particularmente los neoliberales, tienen la misma actitud de desprecio a los derechos de la mayoría.

Julio Boltvinik

\section{POBREZAY CINISMO EN LA MUNDIALIZACIÓN CAPITALISTA CONTEMPORÁNEA}

$\mathrm{N}$ unca como ahora en la historia de la modernidad se había presentado tan polarizado el profundo contraste y la contradicción radical que define una época como la nuestra: con la actual revolución tecnológica - la cuarta en la historia de la mundialización capitalista - cruzamos por el progreso históricamente más avanzado de la técnica planetaria y, sin embargo, a la vez, la depredación del proceso de reproducción social en el planeta ha llegado a su mayor medida geohistórica. La escasez y, como una de las modalidades radicales de ella, la pobreza social — que esa estructura técnica perfectamente podría superar y desactivar-, lejos de estar siendo rebasada se encuentra siendo llevada artificial y agresivamente a una escala previamente inédita. La tercera gran crisis en el desarrollo del capitalismo moderno - la de mayores dimensiones geoeconómicas, ya que, a diferencia de la primera gran crisis (1870-1890) que fue de alcances exclusivamente continentales, pues afectó tan sólo a Europa Occidental, y de la segunda gran crisis (1929-1944), que fue de alcances más amplios pero apenas intercontinentales, ya que impactó además de Europa y Estados Unidos a ciertos países asiáticos como Japón, ha constituido la única crisis de alcances propiamente mundializados— - y junto a ella, de modo decisivo, los mecanismos de contratendencia que el capitalismo implementó para contrarrestarla y apuntalar su poder planetario, es decir, la configuración neoliberal del Estado, la derrota con el "libre comercio" de los monopolios defensivos que edificaron tanto el Tercer como el Segundo Mundos el siglo pasado y la revolución tecnológica de nuestro tiempo — que está llevando más lejos el desarrollo de la subordinación capitalista del proceso de trabajo-, conforman los dispositivos que, a contrapelo de lo que tanto afirma el discurso de la globalización, están marcando la fase actual de la mundialización capitalista como una era que tiene como una de sus peculiaridades históricas justo la mundialización de la pobreza.

De ahí que, a diferencia de las décadas de los sesenta y los setenta del siglo XX —o, dicho más propiamente, del periodo de auge de posguerra - en las que la pobreza, aunque se discutió, nunca estuvo incorporada en la agenda de prioridades estratégicas de los organismos internacionales, a partir de los ochenta y ampliamente desde los noventa, sucede un giro determinado por la asunción de la pobreza mundial como prioridad estratégica en la agenda de estos organismos. Ante todo en el caso del Banco Mundial, esta asunción, lejos de responder a un compromiso genuino con el "humanismo" o el "progreso social" del sistema de naciones, más bien proyecta una necesidad histórica de la fase actual de la mundialización capitalista que, después de haber golpeado y erosionado profundamente el proceso de reproducción de la sociedad planetaria, no ha tenido más opción que reconocer y encarar la pobreza como factor potencialmente desestabilizador del rapport de forces de la "sociedad global"1.

\footnotetext{
${ }^{1}$ Aunque pueden encontrase bosquejos del debate sobre la pobreza internacional a principios de la década de los setenta, como en la Con-
} 
En este escenario histórico, descifrar el sentido estratégico de los programas oficiales de "lucha contra la pobreza” exige reconocerlos no como polo opuesto a la configuración neoliberal del capitalismo contemporáneo, sino, más bien, como su necesario polo complementario. Se encuentran diseñados para enfrentar la agudización y expansión de la pobreza extrema en el orbe no buscando impulsar toda una visión y acción política que permitan sacar eficazmente a los sujetos que la padecen de ese estado de escasez radical, sino contenerlos estratégicamente. De lo que se trata es de imprimirle a la correlación mundializada de fuerzas sociales una configuración que neutralice los potenciales riesgos de inestabilidad que la pobreza extrema acarrea en nuestro tiempo, lo que frecuentemente tiende a convertir los programas de "combate a la pobreza" en programas de "control" o "combate contra los pobres"2.

En este sentido, la línea o el umbral de pobreza extrema que traza el Banco Mundial no responde simplemente al menoscabo de la auténtica magnitud de la pobreza

ferencia de Estocolmo (1972) —plataforma en la creación del Programa de las Naciones Unidas para el Medio Ambiente (PNUMA)—, que tiene la peculiaridad de que concibe la pobreza como la principal fuente causal de la crisis ecológica contemporánea, y que ulteriormente, en el inicio de los ochenta, se abren espacios desde la ONU, de entrada por UNICEF y luego especialmente por el PNUD, para la gestación de relevantes estudios internacionales tanto en torno a la conceptualización como a la medición de la pobreza, sin embargo, el intenso reavivamiento del debate sobre ésta sucede hasta que, como producto de los efectos desplegados por el neoliberalismo, el Banco Mundial se ve obligado a reconocerla como un problema prioritario en su Informe sobre desarrollo mundial 1990. Este constituye, precisamente, el punto histórico específico de partida de la asunción, en la fase actual de la mundialización capitalista, de la pobreza como objeto de una acción estratégica. ${ }^{2}$ Resaltando este efecto, John Toye -investigador de la Universidad de Oxford- apunta: "hay que reconocer que, en los hechos, pocas veces las políticas contra la pobreza son expresión de un impulso puramente humanitario", ya que existen "ciertas condiciones comunes catalizadoras de la acción del Estado para reducir [algún aspecto] de la pobreza. Ellas son [...] la amenaza potencial que representan los pobres, por lo general, en términos de desorden social, y la idea de que el Estado puede modificar la situación [...] La preocupación actual en Francia, y en la Unión Europea, respecto a la exclusión social tiene su punto de partida en la selectividad social que aún persiste en los Estados benefactores europeos [...] El incremento en el número de desempleados de largo plazo, indigentes, desviados y desadaptados sociales, y jóvenes provenientes de familias disueltas amenaza el orden social en los suburbios pobres. Se espera que este riesgo crezca con los cambios estructurales en la economía y los recortes del Estado de Bienestar" (Toye, 2004: 80-81).

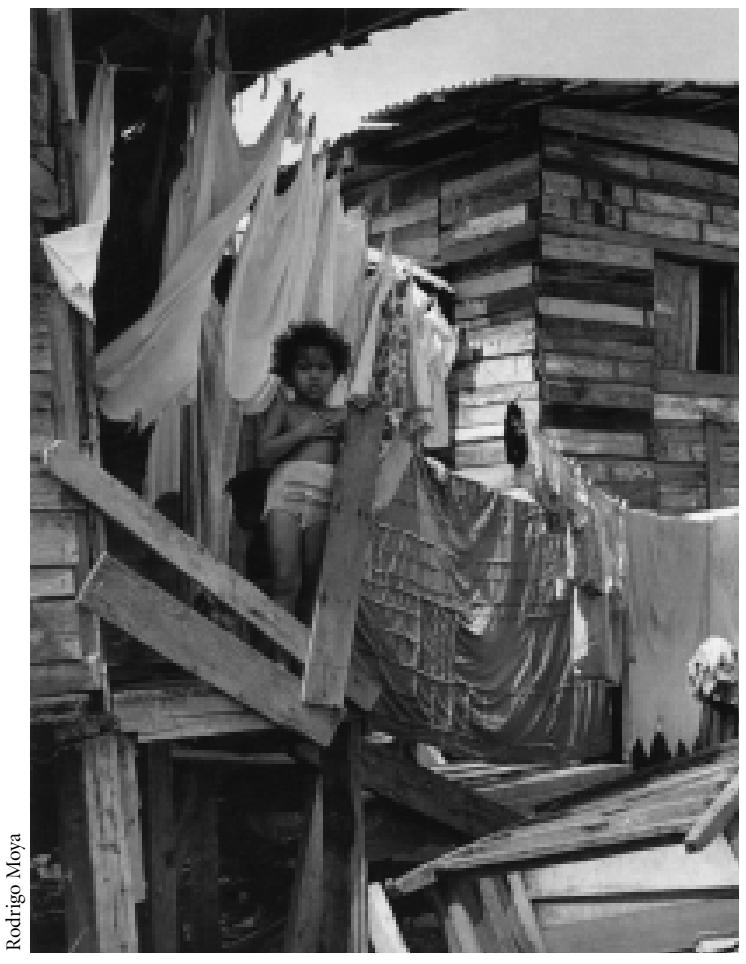

Panamá, Panamá, 1965.

internacional en nuestra época. Verlo así bloquearía captar su efectividad estratégica ${ }^{3}$. Sin dejar de cumplir esa función, va más lejos, puesto que permite explorar y reconocer aquellos puntos del proceso de reproducción social planetarizado en los que se ha llegado a una situación límite, esto es, en los que la amenaza de muerte adquiere un carácter inminente porque ya ni la sobrevivencia puramente animal o no humana es viable ni sostenible para el ser humano.

\footnotetext{
${ }^{3}$ Aunque sugerente porque muestra la incoherencia interna contenida en la concepción de la línea de pobreza extrema trazada por el Banco Mundial — que, por un lado, reconoce que no basta "un nivel mínimo de nutrición" para evaluar la pobreza, y por tanto, que debería considerarse "el costo que implica participar en la vida cotidiana de la sociedad", pero, por otro, desecha absolutamente este costo descalificándolo como "subjetivo"-, no obstante, la crítica de un especialista tan importante como David Gordon — director del Centro Towsend para la Investigación Internacional sobre Pobreza— revela un hiato profundo cuando señala: "Resulta por demás oscuro qué significa la línea de pobreza del Banco Mundial".
} 


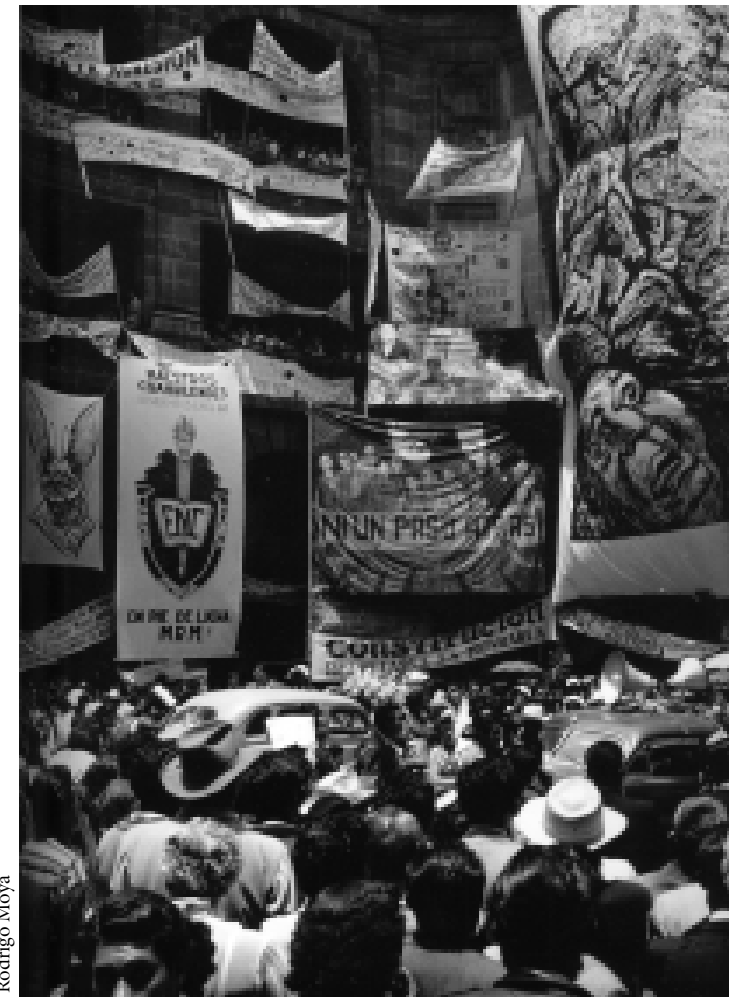

Secretaría de Educación Pública, ciudad de México, 1958.

Precisamente eso es lo que significa definir el umbral de la pobreza extrema con el criterio del ingreso de un dólar diario. Cuando la mirada se niega a quedar entrampada en el formalismo insensible pero también insensibilizador de esta medición e inspecciona el contenido histórico que la determina, puede descubrir que con ella el Banco Mundial introduce una concepción doblemente unidimensionalizada de la pobreza: primero, porque bora o sencillamente ignora todo el amplio conjunto del sistema social de necesidades, reduciendo la pobreza global exclusivamente a pobreza alimentaria; y, luego, porque pasa por alto hasta los medios de subsistencia más básicos requeridos para realizar la alimentación, reduciendo unilateralmente la pobreza alimentaria a adquisición de alimentos no cocinados. Así, el umbral o la línea de pobreza extrema trazada por el Banco Mundial sólo reconoce esta clasificación a un grupo humano si ni siquiera puede adquirir alimentos crudos.
Debajo del discurso "light" que regularmente esgrime el Banco Mundial — presentando la globalización actual como plataforma del progreso mundializado-, la revelación que trae consigo esta perspectiva históricopolítica tácita o implícita pero innegable es, sin duda, ominosa o —como dice Julio Boltvinik— "brutal": la "sociedad global" de ningún modo puede ni debe asumir ofrecer acceso al bienestar a las mayorías, tiene que admitir como inevitable un desdoblamiento y una polarización radical y, en todo caso, pretendiendo hacer manejables los conflictos que esa polarización genera, garantizar a los excluidos exclusivamente el derecho a la sobrevivencia puramente física o animal.

Cuando se va más allá del insensible formalismo de esta línea de pobreza extrema - en la que el monto monetario que la define no revela directamente el contenido real que la caracteriza - y se escudriña en su significado de fondo como modo de administración del proceso de reproducción social en el planeta, puede reconocerse, entonces, que el mirador del Banco Mundial sintetiza o expresa la identidad histórica de una nueva fase de la mundialización capitalista: la fase actual que tiene su especificidad precisamente por ser una mundialización capitalista cínica.

Cínica - en contraste con la forma liberal que activa al "Estado de Bienestar" como contrapeso ante la destructividad económica inmanente a la acumulación del capital — es una configuración histórica del capitalismo que, dejando atrás la promesa que había sostenido en la modernización de la técnica planetaria en su fase previa, es decir, la pretensión de que traería consigo la abundancia para la sociedad en su conjunto, admite sin vacilaciones sus efectos depredatorios contra el proceso de reproducción social y se formula su funcionalización opresiva (Bolívar Echeverría, 1995: 39-40). Dicho de otro modo, cínica es una forma histórica de la modernidad capitalista que parte de la asunción irrenunciable de que el mercado define los muertos y que, sobre ella, se plantea cómo imprimir a su destructividad por principio una forma útil y manejable.

En consecuencia, podría decirse que, como expresión de la necesaria reconfiguración del Estado que requiere la forma cínica del capitalismo, con su abierto elogio al 
laissez faire laissez passer, con su firme rechazo al ejercicio de toda soberanía política, no sólo del sujeto social sino del Estado — que no desactiva sino reconfigura la intervención del Estado en la economía dotándolo de una configuración especificamente autoritaria, esto es, que debilitando sobremanera su función como neutralizador de los antagonismos clasistas se torna funcional al traslado de toda la toma de decisiones al libre juego de fuerzas del mercado mundial, lo que no significa otra cosa más que el traslado autoritario de la máxima autoridad al capital y sus grupos de poder de mayor jerarquía (Horkheimer, 2006)—, es justo el Estado neoliberal — que, en verdad, va en sentido inverso a los principios originales del liberalismo ${ }^{4}$ — el más nítido representante del capitalismo cínico ${ }^{5}$.

\footnotetext{
${ }^{4}$ Demostrando cómo el "neoliberalismo" constituye la negación del liberalismo, en el marco de un análisis de las metamorfosis del Estado moderno en la historia global del capitalismo como sistema-mundo, Wallerstein da cuenta de cómo el Estado liberal — que tuvo como sus soportes la política redistributiva, el derecho al sufragio y la afirmación unificadora de la identidad nacional — surgió como forma de contención política de lo que denomina "clases peligrosas", que ante la masificación de la pobreza y la exclusión en Europa Occidental eran impelidas hacia la revuelta. Periodizando su desarrollo, su crisis y su funcionalidad histórica, muestra que, después de haber servido entre 1848-1914 para "domesticar a las clases trabajadoras de la zona centro" y luego de haberse dirigido entre 1917-1989 a "domesticar el Sur", el colapso contemporáneo del liberalismo, con su desplazamiento por un Estado equívocamente llamado "neoliberal", proyecta el arribo del capitalismo histórico a una compleja situación en la que, precisamente cuando aquella exclusión de mediados del siglo XIX tiende a reactualizarse, pero ahora con una nueva medida geohistórica porque apunta a adquirir una escala mundial, el capitalismo entra al siglo XXI quedándose sin el Estado propiamente liberal que constituyó su "estabilizador esencial" (Wallerstein, 1996).

${ }^{5}$ Para comprender el cinismo a partir de analizar la historia de la cultura política moderna, polémica pero muy sugerente es la obra de Peter Sloterdijk, Crítica de la razón cínica (2003). Aunque escudriña una compleja relación del cinismo con el fascismo - ya en la figura del nacionalsocialismo con Hitler, ya en la figura del socialismo-nacional o "socialismo en un solo país" con Stalin-, sin embargo, porque tiende a identificarlos no alcanza a esclarecer la differentia specifica que existe entre uno y otro. Podría decirse que como configuraciones históricas de la modernidad capitalista, la diferencia entre cinismo y fascismo reside justo y ante todo en el hecho de que mientras el primero constituye una forma del capitalismo que admite sin reparo ni compensación alguna los efectos destructivos que la acumulación genera sobre el proceso de reproducción social y hasta busca sustraerles un efecto útil, el segundo se caracteriza precisamente por agregarle a la violencia económica silenciosa pero efectiva propia de la modernización capitalista otra violencia de orden político destructivo. Admitir que la modernización capitalista del sistema económico de ningún modo puede traer el
}

Después del Banco Mundial, en mayor o menor medida pero articulados con él, son el grueso de los Estados contemporáneos en Occidente los que mejor proyectan el vuelco histórico que el capitalismo le ha dado a sus políticas económicas a partir de su configuración cínica. Como afirma Bolívar Echeverría:

Desde hace un buen tiempo "la intervención estatal" abandonó las veleidades keynesianas que le llevaron a creer que "hacía la historia", que podía al menos adelantarse a la marcha del proceso económico para prepararle el camino [...] La política económica de los Estados occidentales ha dado un giro histórico que ha cambiado diametralmente su sentido. De administradora de la abundancia posible, es decir, de la promesa inscrita en el progreso de las fuerzas productivas, ha pasado a ser —en curiosa similitud con épocas premodernas - la administradora de una escasez inevitable, el dispositivo que transmite la presencia imperiosa de ésta hacia el cuerpo social, la instancia que media su interiorización en las relaciones sociales de convivencia (1995: 40-41).

Sin embargo, pese a su cinismo histórico o, mejor dicho, precisamente debido a él, con el objetivo de alcanzar cierto consenso los Estados neoliberales lo recubren escondiéndolo bajo el ropaje de lo que puede denominarse el mito de la globalización. Un mito que - como todo mito- invierte la dinámica histórica en curso proyectando la globalización no como fase de apuntalamiento del poder capitalista planetarizado, sino como proceso puramente benéfico de difusión mundial del progreso ${ }^{6}$.

mejoramiento del proceso de reproducción social para las mayorías, que la mutilación y la destrucción de una parte del cuerpo social le es inmanente a su legalidad histórica y asumir activamente en términos políticos esa destrucción, eso es lo que constituye el núcleo esencial del fascismo (Bolívar Echeverría, "Violencia y modernidad", ensayo contenido en su brillante texto Valor de uso y utopía, 1998). En este sentido, ciertamente, el fascismo es sin duda alguna cínico, pero el cinismo no es propiamente fascismo, aunque perfectamente puede operar como caldo de cultivo y potencial antesala histórica de aquél. ${ }^{6}$ Para la presentación de todas las dimensiones del mito de la globalización y la respuesta a la plataforma de su formulación — la imagen de que apenas cruzamos por la "globalización" del capitalismo puesto que el siglo XX constituyó el siglo de la mundialización imposible, presuntamente porque en él el mundo no fue uno sino tres, porque en él el capitalismo desde su Primer y su Tercer Mundos y el socialismo desde el Segundo Mundo pugnaron por su planetarización sin ninguno de los dos lograrlo-, elaboré "La globalización como mito y simulacro 
El discurso del Banco Mundial ejemplifica nítidamente este doble movimiento que oscila entre la mistificación y el cinismo porque, aunque su proyecto de la administración de la pobreza mundializada es innegablemente cínico, insiste en que su estrategia económica globalizadora genera progreso.

Cuando, para construir su interpretación de nuestra etapa, lanza una mirada panorámica sobre la historia económica del capitalismo - periodizándola con tres presuntas “olas globalizadoras" (la primera de 1870-1914, la segunda de 1945-1980 y la tercera de 1980 en adelante, que habrían tenido un interregno en el periodo de entreguerras como proceso desglobalizador)—, retroproyecta sobre toda ella el mito de la globalización, afirmando que, si bien con sus primeras dos olas la globalización se fue abriendo camino para integrar paulatina pero crecientemente la economía mundial, es apenas ahora cuando cuenta con las condiciones para impulsar todas sus potencialidades. En este marco, a partir de que reduce formalistamente la globalización a mero libre curso de flujos - del comercio, del capital y migratorios—, intro-

duce una doble yuxtaposición demagógica que articula: 1) la identificación de globalización con crecimiento económico; y, sobre ella, 2) la identificación de crecimiento económico con reducción de la pobreza en el Estado que logre generarlo. Imprimiéndole una versión singular al mito de la globalización, la función de esta doble yuxtaposición reside en encubrir las formas actuales de apuntalamiento del poder planetario como si estuvieran regidas por una, variable para cada Estado pero prometedora para el mundo, tendencia hacia la globalización de la riqueza ${ }^{7}$.

histórico I" (Arizmendi, 2003a) para demostrar que en el siglo XX el capitalismo, lejos de suspender la mundialización —que lo ha acompañando desde su nacimiento-, la llevó hacia un mayor periodo de desarrollo, asumiendo como su función histórica la expansión de su gran industria por el orbe, pero con base en un peculiar desdoblamiento de sí mismo que implementó su configuración clásica en Occidente mientras adquiría otra configuración como "capitalismo despótico" en Oriente.

${ }^{7}$ Hasta en su título el trabajo más importante del Banco Mundial para analizar la relación entre globalización y pobreza revela esta perspectiva: Globalization, Growth and Poverty. Building an Inclusive World Economy, 2002. Existe una traducción al castellano de la que este organismo no se hace responsable, pero que es de buena calidad: Globa-
Si ya a principios de los noventa esta formulación no correspondía con la mundialización de la pobreza, que desde entonces se convirtió en un problema estratégico para la configuración neoliberal del capitalismo planetarizado, menos corresponde ahora en que es la configuración neoliberal misma la que se está volviendo un problema histórico para el capitalismo mundializado.

\section{EL TRIPLE FUNDAMENTO HISTÓRICO O EPOCAL DE MUNDIALIZACIÓN DE LA POBREZA}

\section{La derrota histórica del doble monopolio defensivo de los Estados-nación del ex Segundo $y$ del ex Tercer Mundos}

Replicando la primera yuxtaposición demagógica que introduce el Banco Mundial, debería decirse que de ningún modo globalización y crecimiento económico son sinónimos, ya que, la primera perfectamente puede darse —en el sentido de apertura de los Estados-nación al libre flujo tanto del comercio como del capital mundial $-y$, sin embargo, el segundo no sólo no suceder, sino incluso paralizarse o hasta revertirse. Es que, como fuerza contrarrestante de su tercera gran crisis - la crisis más amplia que le ha tocado padecer en términos geoeconómicos pero también históricos-, el capitalismo ha tenido que implementar toda una re-estructuración no sólo del mercado mundial sino de la misma gran industria que planetarizó el siglo pasado. Justo esa ha sido la tarea de la nueva fase de la mundialización capitalista que para llevarse a cabo ha recurrido, más que a un deterioro, a lo que propiamente constituye una derrota histórica de los monopolios defensivos que edificaron los Estados-nación del ex Segundo y del ex Tercer Mundos.

Levantados como expresión de una resistencia defensiva ante la supremacía tecnológica del capitalismo metropolitano — que, para acumular vorazmente ganancias

lización, crecimiento y pobreza. Construyendo una economía mundial incluyente, 2002. 
extraordinarias, impone con ella sistemáticamente condiciones de un intercambio desigual en el mercado planetario-, los Estados de los capitalismos periféricos forjaron un doble monopolio: al delimitar el territorio que subordina el capital nacional que los constituye, determinaron su control sobre la fuerza de trabajo que los habita $y$, por tanto, sobre la masa del plusvalor nacional que con ella producen, a la vez que definieron la propiedad del Estado-nación sobre los recursos naturales estratégicos de sus territorios. Enfrentados, en el marco de una situación ineludiblemente desventajosa, con el capital metropolitano - que ejerce todo el poder que le adjudica detentar el monopolio estratégicamente más relevante de la mundialización capitalista, el monopolio de la vanguardia tecnológica-, los capitales periféricos podían cederle valor y plusvalor mediante enormes transferencias comerciales y financieras, pero en la fase anterior de la mundialización capitalista mantuvieron en pie, de uno u otro modo, su doble monopolio defensivo, esto es, el control de su capital productivo estratégico.

Cuando estalla la tercera gran crisis capitalista, los Estados del ex Tercer Mundo ven cómo, a la acumulación de la erosión económica que le generan las enormes transferencias desde el intercambio desigual, se le agrega la acumulación de una creciente deuda que propicia ahora enormes transferencias financieras; casi paralelamente, el subimperio del ex segundo Mundo, la Unión de Repúblicas Socialistas Soviéticas (URSS), ve cómo su competencia geoestratégica con Estados Unidos se torna cada vez más difícil hasta colapsar, justo porque el mantenimiento de su poder militar - tanto en términos de inversión en tecnología estratégica como de financiamiento de sus ejércitos en los Estados-satélite de su cinturón geohistórico- le exige tal derrame de recursos que desestabiliza su sistema económico.

El nacionalismo, entonces, que, además de responder a la resistencia de los capitalismos periféricos, había sido funcional, bajo figuras distintas pero tanto en el ex Tercer como en el ex Segundo Mundos, a la tarea histórica de la anterior fase de la mundialización capitalista — planetarizar la gran industria-, se viene abajo. A la vez que no pueden seguir sosteniéndolo los Estados periféricos, se vuelve anti-funcional para la nueva fase de la mundia- lización capitalista que lo embiste consiguiendo, con base en la erosión acumulada, imponerles a éstos la derrota histórica de su doble monopolio defensivo.

En este contexto, la apertura a la "globalización" de entrada desata todo un proceso de desindustrialización estratégica de esos Estados derrotados, que será seguido por un opresivo proceso de reindustrialización estratégica, que los coloca cada vez más en estos años de inicio del siglo XXI dentro de una nueva forma estructural de subordinación tecnoeconómica ante los capitales metropolitanos. Incapacitados para competir con los flujos comerciales de éstos y apresados por los condicionamientos financieros que se les imponen, los Estados periféricos experimentan, así, un profundo proceso de desestructuración de sus redes tecnológicas que, primero, busca destruir el encadenamiento de ramas y hasta ramas enteras, para, luego, sustituir con nuevos corredores geoindustriales multinacionales y mundializados la estructura de su sistema económico.

Cuando se encuentra en curso el proceso de esa desindustrialización estratégica y la transición hacia su opresiva reindustrialización estratégica, la "globalización" de ningún modo genera crecimiento. Junto a América Latina con su "década pérdida" - que, en verdad, corresponde no a una década sino a dos-, incluso más que ella, la "transición hacia la economía de mercado" de la URSS y los países del Este europeo conforman los ejemplos más dolorosos de este proceso histórico, en el que se combinan la desindustrialización estratégica como fundamento de una enorme ola de desempleo y la privatización de las empresas estatales como fundamento del arrebato de fuentes esenciales de la reproducción social a múltiples naciones. El caso de África subsahariana es aún peor porque, aunque ahí la forma actual de la "globalización” capitalista no se acompaña por ningún proceso de reindustrialización estratégica, el capital metropolitano no tiene reparo alguno en sacar todas las ventajas que le deja el "libre comercio" en un continente condenado a una especie de "apartheid" tecnológico ${ }^{8}$.

\footnotetext{
${ }^{8}$ Reconociendo tácitamente el fracaso de las políticas antipobreza de los organismos internacionales, cuando ese proceso desindustrializador se encontraba en pleno curso, uno de los más altos funcionarios
} 
Desde esta óptica puede valorarse el incisivo balance que realiza Michel Chossudovsky (2002) en su crítica a la estrategia del Banco Mundial. Estrategia en dos etapas, que primero pretende lograr la "estabilización económica” (con devaluación, liberación de precios y austeridad presupuestaria) y luego impone "reformas estructurales" (con liberalización comercial, privatización de empresas estatales y tierras cultivables, desregulación bancaria, reformas laboral y fiscal). Demostrando que, lejos de responder al objetivo de estimular el despegue hacia el desarrollo de los Estados, esta estrategia reconfigura las relaciones del poder global en el mundo, la mirada de Chossudovsky permite reconocer que el Banco Mundial, primero, mediante sus políticas de "estabilización económica”, desestabiliza las bases del mercado interno de los países, para luego, mediante las "reformas estructurales", impulsar el apoderamiento y la recomposición de la base industrial de su capital productivo estratégico. Entonces, la liberalización comercial —que genera desindustrialización estratégica - es seguida con privatización de empresas y procesos productivos, tanto en la industria como en el campo, cediendo su control al capital privado y extranjero en el marco de una re-estructuración de la producción global en el mundo. De ahí que, conforme los Estados se quedan sin capacidad de autogeneración y manejo soberano de recursos propios, el resultado sea una radical desestabilización del proceso de reproducción social de sus naciones que, lejos de traer la globalización de la riqueza, avanza emplazando la "globalización de la pobreza" como peculiaridad histórica de nuestro tiempo 9 .

del FMI declaró: "Con base en los estudios existentes, ciertamente, no podemos decir si la adopción de los programas apoyados por el Fondo llevaron a una mejoría en el comportamiento de la inflación y del crecimiento. De hecho, a menudo se encuentra que los programas están asociados con [...] una caída en la tasa de crecimiento" (Khan, 1990: 196 y 222).

${ }^{9}$ Con cierta afinidad con lo que aquí denominamos derrota del doble monopolio defensivo de los Estados periféricos, Chossudovsky da cuenta de cómo - desbordando los efectos desindustrializadores producidos en el mero apogeo de la Segunda Guerra Mundial— el "ajuste estructural" que se le impuso a la antigua Unión Soviética generó una caída de la producción de tal magnitud que la sumergió en un proceso de "tercermundización" — desatando una reducción de los niveles de vida sin precedentes-; a la par que sus Estados satélites, como Vietnam
En síntesis, fundamento de mundialización de la pobreza no es sólo la represión del salario, también es este complejo proceso de reconfiguración del poder planetario que, al hacer de los Estados periféricos Estados globalizados, los derrota imponiéndoles ya no, como en la fase anterior de la mundialización capitalista, la mera transferencia de importantes porcentajes de su valor y plusvalor nacional al capital metropolitano. Sin dejar de realizarse esa transferencia, la fase actual de la mundialización capitalista va más lejos, ya que, agresivamente los presiona obligándolos a efectuar el traslado de su plataforma económica estratégica a manos del capital privado y extranjero. De este modo, si un Estado va perdiendo gradual pero ampliamente el control de su capital productivo estratégico, es hundido en un estado estructural de impotencia para impulsar su propio desarrollo económico. La ausencia de autodeterminación nacional se convierte, así, en fundamento histórico de un ominoso oleaje de empobrecimiento.

\section{La reconfiguración neoliberal del Estado}

Ahora bien, replicando la segunda yuxtaposición demagógica que introduce el Banco Mundial debería decirse que, como especificidad histórica de la fase actual de la mundialización capitalista, de ningún modo crecimiento económico y reducción de la pobreza corren paralelos.

\footnotetext{
—al que tanto se elogió como un futuro "tigre asiático" gracias a su conversión en "Estado globalizado"-, padecieron la exclusión de los productores nacionales de su propio mercado y una merma drástica de su base industrial nacional generada por el oleaje privatizador. Mientras en América Latina la misma estrategia producía un radical desmembramiento del tejido económico tanto en la industria como en el campo que, a partir de instalar una crisis profunda en la reproducción social, lograba recanalizar las actividades económicas promoviendo crecientemente una riesgosa expansión de la economía ilegal y hasta la configuración de "narco Estados". Cuando África mostraba que el hambre perfectamente podía no ser creada por escasez sino por exceso de alimentos, justo debido a que el "libre comercio" daba entrada a los granos de las transnacionales de Estados Unidos, devastando a los productores autónomos y haciendo estallar la única cualidad de varios países en ese continente olvidado: la seguridad alimentaria. Debido a que se percata de los efectos que produce la desindustrialización estratégica en el marco de la fase actual del capitalismo es que Chossudovsky califica al "ajuste estructural" que con ella se impone como "genocidio económico" (Chossudovsky, 2002). Para constatar que éstos no son casos aislados, sobre el hambre como arma en la fase actual del capitalismo véase el texto colectivo Geopolítica del hambre (1999).
} 
Diferenciándose de los periodos de apogeo que siguieron a las primera y segunda grandes crisis en la historia de su ciclo económico, en los que el Estado liberal y el Estado keynesiano — para dinamizar la realización del plusvalor en el mercado y edificar formas eficaces de contención política de los dominados modernos-intentaron acompañar el crecimiento económico con elevación del estándar nacional de vida, el capitalismo contemporáneo — como lo constata el crecimiento del PIB mundial en estos años (FMI, 2006) — está saliendo de su tercera gran crisis, pero mediante una reconfiguración histórica de sí mismo que acompaña necesariamente el crecimiento económico con la expansión e intensificación de la pobreza en el mundo.

Son dos los fundamentos que generan este resultado histórico: la reconfiguración neoliberal del Estado y el potenciamiento que la actual revolución tecnológica determina del dominio capitalista del proceso de trabajo planetario.

Implementada tempranamente como mecanismo contrarrestante de la crisis capitalista, la reconfiguración neoliberal del Estado asumió desde su inicio como uno de sus ejes la represión del salario tanto directo como indirecto. Deteniendo los ajustes de los salarios con el pretexto de impedir el alza generalizada de precios, hizo de la "lucha contra la inflación" una cobertura funcional a la contención estratégica del salario. Después, complementando este dispositivo con el que reprime el salario nominal que se percibe de modo directo, se implementó otro: la privatización de los servicios que para apoyar el proceso de reproducción nacional (como los servicios educativos y médicos) tiene que brindar el Estado. Lo que no significa otra cosa que activar la represión del salario social indirecto, esto es, del salario que no se percibe como dinero sino como servicio estatizado.

Para desplegar esta privatización el capitalismo recurre a una táctica que se mueve de dos modos: por un lado, explora imponer la privatización directa, esto es, la franca conversión de servicios públicos en privados, pero, por otro, cuando la correlación de fuerzas políticas no se lo permite, recurre a una privatización indirecta, es decir, al desfinanciamiento estratégico programado de los servicios públicos que, al ser asfixiados, empujan la sociedad nacional hacia el consumo de servicios privados.

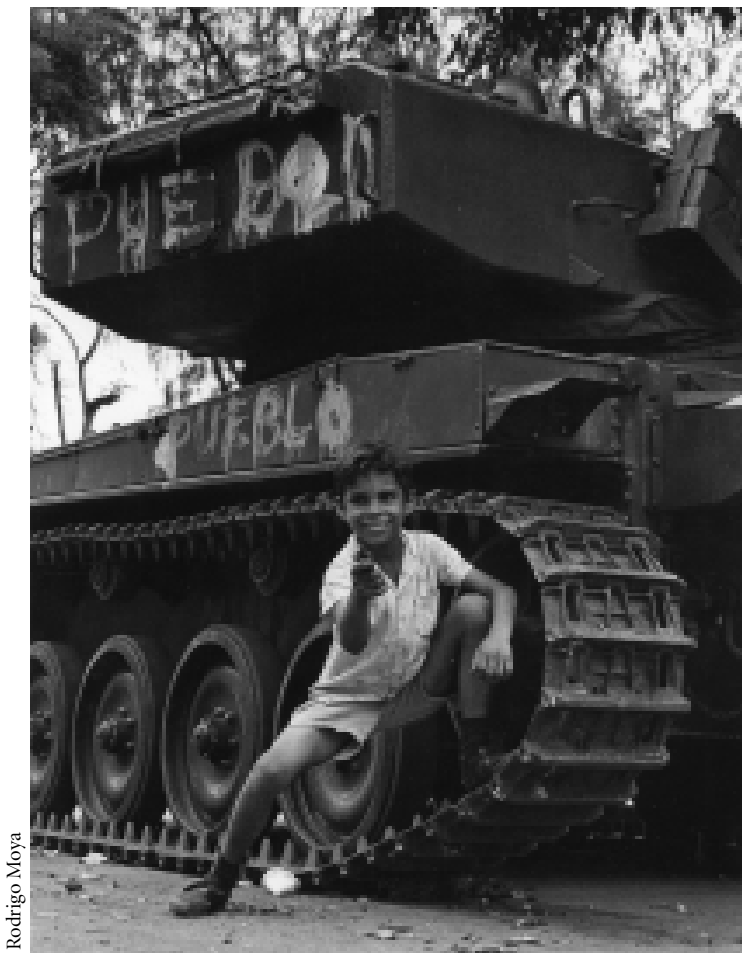

Santo Domingo, República Dominicana, 1965.

En consecuencia, los dos circuitos que constituyen el salario son erosionados y, con base en la reconfiguración neoliberal del Estado, el capitalismo contrarresta la caída de su tasa de ganancia expropiando valor del fondo salarial de consumo para trasladarlo hacia el fondo de acumulación.

El estreno mundial de este modo de operar del capitalismo tuvo lugar, poco después del estallido de la tercera gran crisis, en Chile con el golpe de Estado de 1973. Lo primero que hizo el gobierno militar fue disparar (casi en un $300 \%$ ) el precio del pan y contener los salarios ${ }^{10}$. De

\footnotetext{
${ }^{10}$ En "Modo de producción estatal y satisfacción de necesidades esenciales en México" (1986: 195-244), Julio Boltvinik demostró que las empresas estatales pueden vender más barato que las privadas porque sólo necesitan recuperar los costos de producción sin necesariamente obtener la tasa media de ganancia. Formulación que perfectamente se articula con la que planteo aquí sobre el Estado que, como personificación del capital social nacional, tiene que encargarse del salario indirecto como dimensión del valor de la fuerza de trabajo.
} 
allí en adelante los alcances geohistóricos de esta ofensiva contra el salario internacional han sido de tal magnitud que, además de extenderse por América Latina y persistir en el tránsito de dictaduras militares a gobiernos civiles - que ya no necesitan de violencia política destructiva para implementarla porque ya quedó modificada la correlación de fuerzas clasistas-, llega a las demás zonas del Tercer Mundo, penetra incluso el Primer Mundo mismo ${ }^{11}$ y hasta cruza las fronteras del Segundo Mundo cuando se viene abajo.

Lo peculiar, lo característico de este proceso reside en que la reconfiguración neoliberal del Estado como mecanismo estratégico de contención del salario persiste más allá del periodo de crisis, aun cuando el capitalismo entra en un nuevo - pero necesariamente temporalperiodo de auge económico. Así, la reconfiguración neoliberal del Estado contribuye esencialmente a definir la especificidad histórica de la nueva fase del capitalismo mundializado como un tiempo en el que la reducción de la pobreza no acompaña al crecimiento económico ${ }^{12}$.

${ }^{11}$ Es de tal magnitud el avance sin parangón de la pobreza actualmente en Estados Unidos — desde Detroit, Filadelfia o Chicago en el norte, hasta Nueva Orleáns, Denver o Phoenix en el sur, pasando por Washington-que ciertos grupos de la clase política empiezan a realizar cuestionamientos en torno a lo que llaman un "asalto a los programas de las clases pobre y media" que hace que, habiendo crecimiento económico, aquella crezca (Tritch, 2006).

${ }^{12}$ Desde un ángulo distinto, Peter Towsend y David Gordon — dos de los especialistas más connotados en el estudio contemporáneo de la pobreza mundial - certeramente denuncian que, pese a que "el nivel de recursos mundiales es enorme y continúa creciendo", "las tendencias de los niveles de vida en el mundo nos llevan a una perturbadora conclusión: la pobreza generalizada está para quedarse y, lo que es peor, para crecer". Mientras Townsend — partiendo del análisis de Galbraith (The Nature of Mass Poverty, 1979) que identifica al poder corporativo como causa principal de la pobreza generalizada - insiste en que "el poder ejercido por las mayores corporaciones transnacionales, la obstinada estrategia económica impulsada" por el Banco Mundial, "las restricciones impuestas a las Naciones Unidas" y el "desvergonzado control sobre el comercio mundial" que ejerce Estados Unidos y el Grupo de los 8 , "deben ser investigados [...] si es que se desea explicar adecuadamente los fracasos de las políticas para combatir la pobreza”. David Gordon - partiendo de recuperar la periodización trazada por Stiglitz (en More Instruments and Broader Goals: Moving Towards a post-Washington Consensus, 1998) — señala que la estrategia neoliberal ortodoxa se desdobla en cuatro etapas: 1) privatización —que, dejando al Estado sin empresas nacionales, eleva los precios de los bienes y servicios consumidos por los pobres-; 2) liberalización del mercado de capitales - que dota a los especuladores de un nuevo poder para desestabilizar economías nacionales_; 3) precios basados en el mercado

\section{La actual revolución tecnológica como fundamento de la correlación entre pobreza y mundialización}

Al lado de la reconfiguración neoliberal del Estado —más aún, determinándola—, esta peculiaridad de la fase actual del capitalismo tiene en la revolución tecnológica, con la teleinformática y la biotecnología, su soporte profundo. El fundamento histórico que soporta esta configuración que correlaciona mundialización de la pobreza y crecimiento económico es, entonces, tecnopolítico.

Desde la teleinformática —esto es, desde las tecnologías de la información redefinidas por la microelectrónica y vinculadas a la red de comunicación global fundada por la Internet—, el capitalismo ha impulsado la informatización del proceso productivo planetarizado, implementándola como punta de lanza de una agresiva ofensiva contra la clase trabajadora. Toda una reestructuración que, en el marco de la articulación a distancia pero en tiempo real del proceso productivo, le permite realizar la deslocalización de sus diversas etapas fabricando una pieza en un país y otra en otro para ensamblarlas todas en un tercero, de modo que, la informatización lo ha dotado de un mayor poder, con el que logra confrontar a los trabajadores modernos al interior de un mercado laboral mundializado pero fragmentado $-\mathrm{o}$ sea, cada vez más abierto al libre desplazamiento del capital productivo hegemónico pero cerrado al libre movimiento internacional de la fuerza de trabajo. Como el capital ha adquirido una agilidad inédita para trasladarse de un Estado a otro - lo que de ningún modo significa que apenas haya estrenado su capacidad de desplazamiento, sino que la ha llevado a una nueva medida histórica一, al poder ex-

\footnotetext{
-que disparan los costos de bienes básicos como los alimentos y los energéticos, provocando frecuentemente disturbios-; y 4) libre comercio - que consolida la integración de una nueva correa de poder desde la cual la OMC domina el comercio en el mundo con una "situación de peligrosa desventaja para los países más pobres”- Por eso, con base en el Human Development Report 1999 del PNUD, concluye: "a pesar de las ventajas del libre comercio, la historia ha mostrado que sus resultados han sido a menudo graves hambrunas y pobreza creciente". Véanse sus interesantes ensayos "La medición internacional de la pobreza y las políticas para combatirla" (Townsend, 2004) y "Construyendo una estrategia para combatir la pobreza” (Gordon, 2004).
} 
portar casi cualquier etapa del proceso productivo para buscar hacia cualquier latitud la fuerza de trabajo que mayor represión acepta de su salario, activa una dinámica de intensificación de la competencia en el mercado laboral mundializado con la que consigue imponer el recrudecimiento de la represión salarial en los capitalismos periféricos, al mismo tiempo que, penetrando tanto en Estados Unidos como en Europa, introduce esta represión en el capitalismo metropolitano.

Buscando descifrar la especificidad histórica de esta represión salarial mundializada, Chomsky la califica como "el regreso del capitalismo salvaje", aunque es más que eso.

Al lanzar una mirada panorámica al desarrollo de la sobre-explotación desplegada en el curso de la mundialización capitalista, podría decirse que cabe conceptualizar su historia desdoblándola en tres periodos.

Primero, el periodo de la sobre-explotación concentrada en la metrópoli (1740-1880). Corresponde a la génesis y la consolidación geohistórica de la gran industria en Europa Occidental, que le permitió al capitalismo instaurar la modernización tecnológica como plataforma para desarrollar la explotación de plusvalor en todas sus formas - no sólo absoluta, sino también relativa y extraordinaria-, a la par que, traicionando tempranamente sus promesas de igualdad, lo dotó de las condiciones históricas para embestir la ley del valor -o sea, el intercambio equivalencialen la relación contractual de la clase trabajadora con el capital. Instalando sobre la explotación del plustrabajo impago un proceso de otro orden, articulado con él pero distinto y espurio, el capitalismo refuncionalizó el oleaje de desempleo producido por su modernización tecnológica como mecanismo con el cual logró imponer un violento arrebato o, dicho de otro modo, un robo de importantes porcentajes del valor de la fuerza de trabajo al salario. Sobre-explotación, entonces, no es sinónimo de una gran tasa de explotación. Más bien, significa articulación de explotación de plusvalor con expropiación de valor al salario. Da cuenta de una agresiva recanalización que sustrae recursos del fondo social de consumo para dirigirlos hacia el fondo capitalista de acumulación ${ }^{13}$.

${ }^{13}$ Esta es la fase de la sobreexplotación que Marx analiza directamente dando cuenta del impacto desvalorizador de la modernidad capitalista
Segundo, el periodo de la sobre-explotación concentrada en la periferia (1880-1970/1980). Cuando, en el marco del auge abierto en las últimas décadas del siglo XIX, el desarrollo del capitalismo industrial europeo y estadounidense, para dinamizar la realización del plusvalor al interior de sus propias economías nacionales, requirió elevar los niveles de vida desactivando la sobre-explotación impuesta en la fase anterior contra la clase trabajadora de sus Estados. Sin embargo, lejos de superarse, la sobre-explotación se neutralizó en la metrópoli pero para efectuar su traslado a la periferia. Acorralada por la constante violación de la ley del valor que se impone en el mercado mundial, en el que el capital de la metrópoli hace valer su supremacía tecnológica o instrumental arrebatándole el continuo pago de un tributo y, por tanto, la cesión crónica de enormes masas de valor y plusvalor, la periferia responde a esa violación de la ley del valor, que erosiona sus procesos de acumulación, duplicándola. Regresa al interior de sus Estados nacionales transgrediendo el intercambio equivalencial con su propia clase trabajadora para hacer de la expropiación de valor al salario un mecanismo de cierta efectividad en la compensación de las constantes pérdidas que padece en el intercambio desigual dentro del mercado mundial. En el curso de este periodo, la sobre-explotación, así, quedó trasladada geohistóricamente volviéndose un dispositivo permanente o estructural del capitalismo periférico.

Tercero, el periodo de la mundialización de la sobre-explotación del trabajo (de 1980 en adelante). A partir del cambio de siglo, más que regresar al primero de estos periodos, la teleinformática le ha inscrito al desarrollo de la sobre-explotación un alcance hasta entonces inédito: desbordando sus anteriores medidas geohistóricas, que siempre fueron circunscritas o no planetarizadas, la ha llevado a combinar su recrudecimiento en el capitalismo periférico con lo que, más bien, constituye su reedición gradual pero creciente en el capitalismo metropolitano - en el que el

sobre la fuerza de trabajo masculina, que conduce a la creciente integración del resto de la familia a la producción de capital para extender la violación de la ley del valor en la relación del capital con el trabajo femenino y, ante todo, con el trabajo infantil (El capital, 1981: libro I, vol. 2, cap. XIII, \$3). 
capital ahora la reactualiza, o sea, la vuelve a poner en acto, violando el intercambio equivalencial ya no sólo contra los migrantes extranjeros, que fue exclusivamente contra quienes la aplicó en el periodo anterior, sino incluso contra sus propios ciudadanos. La especificidad de este último periodo, entonces, reside en que el capitalismo, por primera vez en la historia económica moderna, dota a la sobre-explotación de un alcance planetario ${ }^{14}$.

Ahora bien, la actual revolución tecnológica opera como fundamento de la mundialización de la pobreza no sólo mediante este impacto histórico generado por la teleinformática. Al lado de ella, la biotecnología contribuye a través de una doble vía. Por un lado, porque después de siglos de un acorralamiento con el que el capitalismo condujo a las etnias indígenas a implementar la coexistencia de la producción colectiva de bienes para autoconsumo con una relación siempre inestable entablada con el mercado laboral como estrategia mínima de sobrevivencia histórica, y con la conversión de los territorios que

${ }^{14}$ Un alcance irreconocible en la expresión "regreso del capitalismo salvaje" que, pese a tener el mérito de resaltar la transgresión de los derechos laborales en la relación capital/trabajo, no proyecta la nueva medida - ya mundial — de la sobre-explotación. Sin embargo, en el caso de Chomsky este es un problema propiamente terminológico, ya que, cuando habla de que el capitalismo en la metrópoli lo que ha hecho es "traer el Tercer Mundo a casa", reconoce la mundialización de la miseria contemporánea como especificidad de nuestra era. Su explicación de la miseria en los guetos urbanos se basa en dos procesos de ritmos históricos disímiles pero articulados. En primer lugar, en el desarrollo interno del capitalismo estadounidense que, a partir de la Gran Depresión y, ante todo, del auge de posguerra, ha desplegado un crecimiento económico que, por cargarse hacia el sector servicios y la industria de alta tecnología vinculada al sistema militar, ha perdido su capacidad de absorción de nuevas oleadas de inmigrantes - revirtiendo la capacidad que tuvo en el siglo XIX y principios del XX por la gran demanda de trabajo manual que exigió tanto la construcción y consolidación de su sistema fabril como la dinámica de su sector agrícola- Esto se complicó debido al amplio oleaje de inmigración "interior" que tuvo lugar porque una acelerada mecanización de la agricultura en el Sur expulsó la población negra — anteriormente esclava — empujándola hacia las ciudades del norte y, asimismo, porque la inmigración exterior ha persistido cuando las opciones laborales se van cerrando en Estados Unidos. En segundo lugar, en la proyección mundializada del capital estadounidense que usa la deslocalización del trabajo como arma de represión salarial. De ahí que, con estadísticas sobre la expansión del hambre y citando la investigación que para el Fondo de las Naciones Unidas para la Infancia realizó Sylvia Ann Hewlett en torno al trato de los niños en "países ricos" (Child Neglect in Rich Nations, 1993), afirme que el capitalismo estadounidense está embarcado en "una guerra contra los niños y las familias” (Chomsky, Obra esencial, 2003: 62-67 y 432-441). habitan en recurso estratégico, debido a la información genética que contienen en su biodiversidad, el capitalismo se ha planteado su expropiación desatando una presión sobre estos conjuntos étnicos que apunta a llevar a una situación límite, definitivamente insostenible, la pobreza que históricamente han padecido. Por otro lado, si ya, en el marco de su etapa neoliberal, el capitalismo se había embarcado en un ataque masivo a la producción campesina del ex Tercer Mundo para trasladar a los capitales metropolitanos el control del mercado mundial alimentario, con la biotecnología apunta a llevar mucho más lejos ese proceso colocando la producción campesina de la periferia en un estado de dependencia radical. A partir de la invención de los cultivos transgénicos Terminator, ha creado semillas "suicidas" — que únicamente duran un solo ciclo productivo, lo que crea dependencia respecto de la corporación multinacional que genera los aprovisionamientos—-, semillas condicionadas agroquímicamente — que no crecen a menos que se cultiven utilizando fertilizantes producidos por la misma corporación que las comercializa-y, por si fuera poco, además ecocidas - que depredan las variedades tradicionales. A través de estas mediaciones busca consolidar la instalación de lo que constituye una nueva dependencia tecnoalimentaria centro-periferia —en gestación en el curso de las últimas dos décadas - que abre un amplio canal de acumulación al capital metropolitano, a la vez que levanta un gran oleaje de empobrecimiento por la devastación que acarrea sobre la producción rural periférica.

De este modo, entre la ampliación del ejército internacional de reserva y la mundialización de la sobre-explotación del ejército de trabajadores en activo que ha estado generando la teleinformática, y entre la pauperización de la producción campesina y la expropiación capitalista de recursos naturales estratégicos que viene impulsando la biotecnología, a lo que habría que agregar la explosión de conflictos bélicos por la disputa de yacimientos energéticos, el capitalismo contemporáneo está conformando auténticos "agujeros negros" en los que la pobreza extrema impacta el sistema de convivencia social sometiéndolo a la devastación.

Así, lo que Nigel Harris (1987) calificó como la muerte o el "fin del Tercer Mundo" ha quedado acompañado 


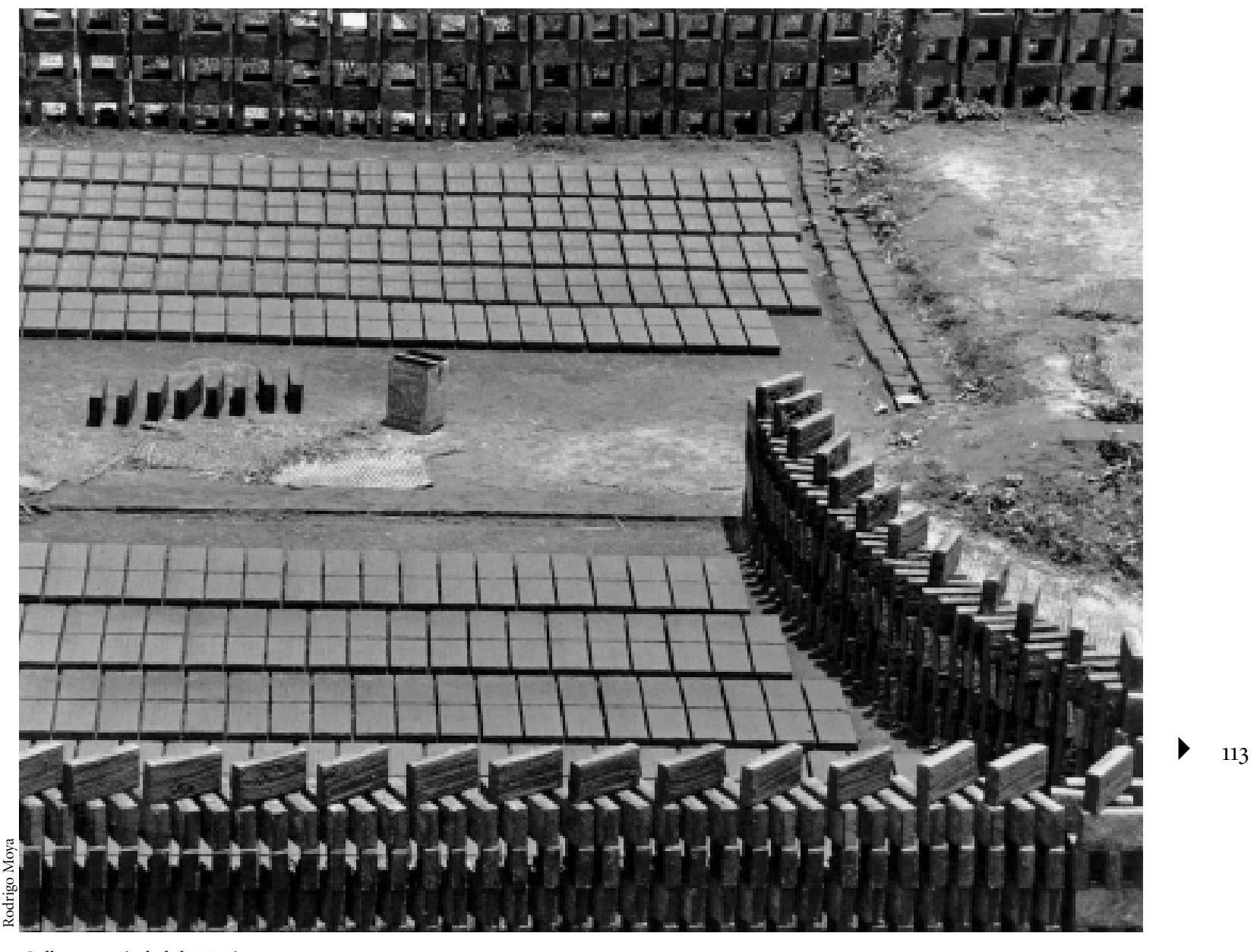

Culhuacán, ciudad de México, 1960.

por el nacimiento del Cuarto Mundo. Un "mundo", a diferencia de los tres "mundos" que caracterizaron al siglo anterior, que no posee fronteras circunscritas e incluye por igual zonas tanto de las periferias como de los centros del capitalismo contemporáneo. En el que, por contraste con la segregación tradicional — determinada en función de la identidad étnica, racial o religiosa—, la exclusión -que, en tanto producto de la actual revolución tecnológica, no constituye un fenómeno ajeno sino integrado a la fase actual de la mundialización capitalista — impacta a barrios, ciudades, Estados y hasta regiones enteras. Puede reconocerse en las favelas brasileñas y en el sur del Bronx, en Burkina Faso y en La Courneuve, en Kamaga- saki y en Chiapas, en Sachsen-Anhalt y en el sur de Irak (Castells, 1999: cap. 2) ${ }^{15}$.

\footnotetext{
${ }^{15}$ Aunque sugerente porque asume el reconocimiento de que, una vez sucedido el derrumbe de la Unión Soviética, el desdoblamiento del mundo en tres Mundos ya no responde a nuestra época, la noción del "fin del Tercer Mundo" — que Castells retoma de Harris— introduce la ilusión de que su derrumbe desactiva las relaciones de poder centro-periferia y, por tanto, que asistimos a un proceso histórico de "nivelación de oportunidades económicas". Por eso, problematizando su conceptualización para demostrar que, lejos de su desactivamiento, más bien sucede el apuntalamiento histórico de las relaciones de poder centro-periferia, Giovanni Arrighi y Beverly Silver prefieren hablar de la "extraña muerte del Tercer Mundo". Véase mi traducción de "Trabajadores del norte y del sur", 2005.
} 
Justo es lo que reconoce un importante documento estratégico elaborado por la Agencia Central de Inteligencia de Estados Unidos (CIA) al evaluar las tendencias a mediano plazo de la revolución tecnológica capitalista en el siglo XXI, Global Trends 2015:

En contraste con la Revolución Industrial, el proceso de globalización es más compacto. Su evolución será rígida, marcada por una volatilidad financiera crónica y una brecha económica creciente [...] Regiones, países, y grupos que se sientan dejados de lado enfrentarán una profundización del estancamiento económico, la inestabilidad política y la alienación cultural. Fomentarán extremismos políticos, étnicos, ideológicos y religiosos, junto con la violencia que generalmente los acompaña [...] Obligarán a Estados Unidos y otros países desarrollados a mantenerse enfocados en los desafíos del "viejo mundo", mientras se concentran, al mismo tiempo, en las exigencias tecnológicas de un "nuevo-mundo" [...] A Estados Unidos, como poder global, no le quedará más alternativa que comprometer a los actores principales y confrontar los problemas en ambos lados de la brecha económica y digital creciente en el mundo de 2015, cuando los beneficios de la globalización estarán muy lejos de ser globales (CIA, 2000: 7-8 y 14).

En conclusión, la articulación de la configuración neoliberal del Estado, la derrota de los monopolios defensivos tanto del ex Segundo Mundo como del ex Tercer Mundo y la actual revolución tecnológica constituyen el triple fundamento de la mundialización contemporánea de la pobreza que, a más de dos décadas de estar en curso, ha llegado tan lejos que ha abierto el choque de dos tendencias contrapuestas que pugnan por la definición de la configuración histórica del capitalismo para las siguientes décadas. Una es justo aquella que, ante la intensificación de las contradicciones producidas por la configuración cínica o neoliberal, busca adelantarse preventivamente para neutralizar la explosión de conflictos mayores y que presiona apuntando a reactualizar, de uno u otro modo, el proyecto del Estado regulador interventor en la economía, con el objetivo de instalar toda una reconfiguración del proceso capitalista de acumulación que modere sus efectos destructivos sobre el proceso de reproducción social en el planeta ${ }^{16}$.

${ }^{16}$ Véanse Joseph Stiglitz, 2002; George Soros, 1999; Gérard Kébabdjian, 2006.
Otra es aquella tendencia que, enfrentada a la anterior y por lo pronto venciéndola, viene avanzando aferrándose a la agresiva persistencia de la mundialización capitalista cínica y, justo por eso, estimula los riesgos que abre la dinámica capitalista que viene empujando por la reedición del fascismo ahora a escala planetaria ${ }^{17}$.

Siendo ya delicado el choque que entablan estas dos tendencias entre sí, sin embargo, el proceso histórico en curso en este inicio de siglo es aún más complejo, ya que lo define la conformación de una doble encrucijada yuxtapuesta. Sobre la primera encrucijada, regida por la tensión entre dos modalidades contrapuestas —una neokeynesiana, otra neofascista- de la misma mundialización capitalista, se instala una segunda, en la que no se juega simplemente la lucha por la definición de una u otra forma capitalista, sino la disyuntiva entre una forma de la modernidad que apuntale el dominio capitalista del planeta y otra que instaure como su principio rector el mejoramiento cualitativo del mundo humano de la vida. Es que ahora que la modernidad capitalista ya ha logrado mundializar su gran industria, apunta a generar una situación similar a la que vivió cuando extendió su gran industria sobre Europa, es decir, tiende a hacer de la continua modernización capitalista de la estructura económica fundamento de una enorme masificación internacional de la pobreza. Mutatis mutandis, el siglo XXI tiene en 1848 una imagen en la que se refleja (Wallerstein, 2001). En una era así la construcción de un horizonte crítico transcapitalista en la conceptualización de la pobreza contemporánea se ha convertido en una imperiosa necesidad histórica ${ }^{18}$.

\footnotetext{
${ }^{17}$ A partir de recuperar y polemizar con el incisivo análisis de Carl Amery, Auschwitz, ¿comienza el siglo XXI? (1998), presenté una conceptualización de la revolución tecnológica contemporánea como fundamento de la tendencia a la reedición mundializada del nazismo, aunque con figuras históricas distintas a las que adquirió en el siglo anterior: Arizmendi, 2003b.

${ }^{18}$ La dimensión complementaria de la depredación capitalista del proceso de reproducción de la sociedad mundializada la constituye la depredación capitalista de la objetividad natural del planeta. De ésta, el sobrecalentamiento producido por el patrón tecnoenergético fosilista conforma el proceso que mayores riesgos históricos acarrea. Por eso, en "La crisis ambiental mundializada en el siglo XXI y sus disyuntivas" (Arizmendi, 2006) presenté la formulación de que nuestro tiempo enfrenta una doble encrucijada yuxtapuesta: 1) la encrucijada en la que chocan dos configuraciones diversas de la misma modernidad ca-
} 


\section{EL FLORECIMIENTO HUMANO COMO MIRADOR ICONOCLASTA}

A diferencia de otros miradores que cuestionan la mundialización de la pobreza, pero por los riesgos de inestabilidad histórica que significa para la mundialización capitalista, con su más reciente obra Julio Boltvinik ha creado lo que cabe calificar como todo un nuevo mirador iconoclasta: Ampliar la mirada, sin duda el magnum opus de su prolífica trayectoria, constituye una obra monumental que presenta el proyecto fundacional de crítica de la pobreza desde una perspectiva fundamentada en la trascendencia humana. Se trata de una obra que, a contrapelo del cinismo histórico de nuestra época, redimensiona la conceptualización de la pobreza criticándola, pero desde la riqueza humana, es decir, que coloca como objetivo de su perspectiva no la superación unidimensionalizada de la pobreza extrema alimentaria, ni siquiera de la pobreza de múltiples necesidades básicas o de la —más amplia aún- pobreza económica, sino que se plantea la superación de toda pobreza humana.

Avanzando a contracorriente de la mirada hegemónica del discurso del poder para concebir la pobreza, Boltvinik demuestra que la pobreza es irreductible a la dimensión del estar, que de ninguna manera se remite a un estado compuesto sólo por pobreza de objeto, y por tanto, que la pobreza en la dimensión del estar siempre tiene su otro lado en la dimensión del ser. Esto significa que una

pitalista — una altamente depredatoria, cínica y tendencialmente fascista, contra otra que apunta a moderar la depredación capitalista del planeta-; a la vez que, entrecruzada con ella, se despliega: 2) una encrucijada distinta en la que chocan dos configuraciones contrapuestas de la modernidad —una capitalista, otra anticapitalista—. El contenido de un planteamiento así es antideterminista. Se reconoce que la actual depredación mundializada es en tal escala inédita que acarrea enormes desequilibrios no sólo para el proceso de reproducción de la sociedad sino también ya para la acumulación planetarizada, pero de allí no se infiere una salida predefinida. Se insiste en que la historia no es destino y, por tanto, que la crisis histórica del capitalismo es posible pero también su reconfiguración histórica. Y que esa reconfiguración, a su vez, tampoco está pre-decidida, es decir, que oscila entre la posibilidad de una reconfiguración que modere su depredación del planeta y una tendencia tecnofascista. En síntesis, se mira la historia del siglo XXI como una historia abierta, en la que sus trayectorias de ningún modo se encuentran predeterminadas y dependen de la acción o inacción del sujeto histórico. concepción radical de la pobreza, una concepción que vaya a su raíz, tiene que cuestionar la pobreza en el sujeto: la limitación represiva de su humanidad, tanto de sus necesidades como de sus capacidades, que asfixia y marchita sus potencialidades históricamente determinadas. Lo anterior implica que, colocándose en el debate de frontera sobre la pobreza mundial, en los linderos del conocimiento histórico desarrollado para conceptualizarla y medirla, desplegando una impresionante contribución erudita para llevarlos más lejos, Julio Boltvinik percibe y apunta que la gran limitación del debate contemporáneo en torno a la pobreza reside en que siempre la unidimensionaliza reduciéndola al plano del estar. Como si la humanidad del sujeto fuera irrelevante y no importara. Justo porque es pobre la concepción hegemónica de la pobreza, insiste en fundar un mirador iconoclasta que asuma la necesidad histórica de redefinir los fundamentos de la concepción de la pobreza, ya que ésta sólo puede ser radicalmente encarada si se abre camino al libre despliegue multidimensional del sujeto social: en síntesis, si el florecimiento humano pasa a ser la piedra angular de la perspectiva.

A la hora de realizar una evaluación panorámica del proyecto teórico-crítico de Ampliar la mirada, podría decirse que son, ante todo, cuatro los principios decisivos desde los que despliega su contribución al debate mundial del siglo XXI sobre la pobreza: 1) el principio de la totalidad;2) el principio de la transdisciplinariedad;3) el principio de la economía moral; y 4) el principio de la soberanía. Todos los cuales responden al profundo proyecto crítico de pensar la pobreza en clave de valor de uso.

\section{El principio de la totalidad}

Presionados por la época, enfrentados a una historia — la del capitalismo neoliberal- que acrecienta e intensifica la pobreza, por derroteros distintos, Julio Boltvinik y Samir Amin confluyen en una formulación central: los soportes de la ciencia económica predominante, convencional o "principal" (mainstream economics) estallan y ponen al descubierto su impotencia histórica para descifrar la pobreza en una era como ésta. Mientras Samir Amin cuestiona el mirador de la "teoría económica con- 


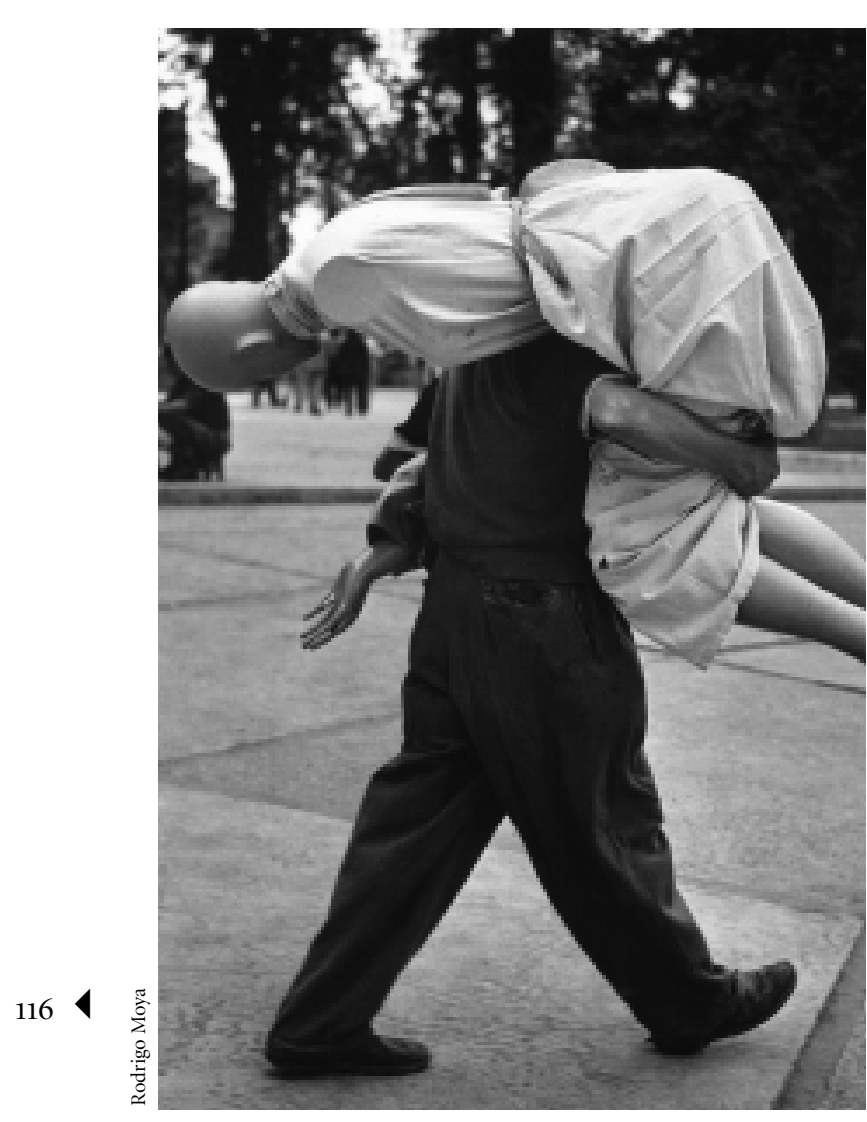

Alameda Central, ciudad de México, ca. 1964.

vencional" porque regularmente ofrece una explicación no económica de la pobreza mundial, adjudicando su fundamento de manera neomalthusiana al crecimiento poblacional o simplistamente al diseño de estrategias políticas erradas, revelando así su impotencia histórica para descifrar la mundialización de la pobreza desde la legalidad de la propia acumulación del capital (Amin, 2003); Julio Boltvinik critica el soporte estructural de toda la economía "neoclásica", la teoría de la utilidad subjetiva, demostrando su impotencia para teorizar la pobreza justo porque rechaza el concepto de necesidad material sustituyéndolo por el de preferencia, es decir, por el capricho psicológico del consumidor, lo que introduce un subjetivismo que torna volátil todo el sistema de requerimientos humanos dejando la pobreza real sin base objetiva y, por tanto, desfigurando su conceptualización para reducirla a un mero problema de interpretación ${ }^{19}$. Como puede verse, por caminos diversos, Amin y Boltvinik confluyen en el reconocimiento de que la pobreza en la fase actual de la mundialización capitalista ha puesto en crisis los fundamentos de la economía convencional y, en consecuencia, se ha vuelto imperiosa la necesidad histórica de redefinición de los fundamentos del mirador desde el que se le analiza.

Más aún si se toma en cuenta que el relativismo subjetivista está en apogeo. Desde la visión de la economía convencional, permea la perspectiva de múltiples organismos internacionales - como la Organización para la Cooperación y el Desarrollo Económico (OCDE) y la Unión Europea- que, introduciendo delimitaciones propiamente arbitrarias del umbral de pobreza — para las cuales seleccionan sin ninguna base una proporción de la media o mediana del ingresosunta imposibilidad para reconocer sólidamente el sistema social de necesidades.

En el itinerario crítico-intelectual de Julio Boltvinik, el proyecto de esta redefinición de los fundamentos del mirador para estudiar la pobreza de ningún modo apenas comienza. Se encuentra presente desde el inicio histórico de sus contribuciones al debate de frontera internacional.

De hecho, si periodizamos la historia de su proyecto crítico de la pobreza, podría decirse que han sido tres las etapas que rigen su desarrollo.

Primera etapa. La fundación de una nueva mirada: el proyecto de estudio de la pobreza en clave de valor de uso.

Negándose por principio al análisis destotalizador, preponderante desde inicios de los ochenta, que aborda la pobreza unidimensionalizándola desde el método de Línea de Pobreza (LP) — que procede como si su única determinante proviniera de los límites del ingreso co-

\footnotetext{
${ }^{19}$ Mundo Siglo XXI, la revista del Centro de Investigaciones Económicas, Administrativas y Sociales del Instituto Politécnico Nacional, tuvo el honor de publicar de Julio Boltvinik el ensayo en el que, cuestionando la piedra angular de la economía convencional, la teoría del consumidor, presenta un adelanto de Ampliar la mirada: "El rechazo al concepto de necesidades humanas", 2006a.
} 
rriente- o desde el método de Necesidades Básica Insatisfechas (NBI) —que procede como si la única determinante de las condiciones sociales de vida proviniera de los servicios que brinda el Estado (como educación y salud) y del patrimonio básico de los hogares-, Julio Boltvinik, ya en sus primeros trabajos, busca superar estas visiones regidas por la parcialidad colocando novedosamente como fundamento heurístico de sus investigaciones el principio de la totalidad.

Inaugurando su implementación el estudio de las necesidades esenciales para la Coordinación General del Plan Nacional de Zonas Deprimidas y Grupos Marginados (Coplamar) adopta una doble perspectiva que corre paralela complementándose, esto es, utiliza tanto el método LP como la variante sectorial fragmentada del método NBI (como él mismo la denomina) ${ }^{20}$.

No bastaría decir que la adopción de esta doble perspectiva complementa el estudio de la pobreza en clave de valor (ingreso corriente) con su estudio en clave de valor de uso (servicios y patrimonio). Tampoco que complementa el estudio de la pobreza desde el circuito del salario directo (ingreso corriente) con su estudio desde el circuito del salario indirecto (servicios públicos). Es mucho más profundo el significado histórico de esta innovación, precisamente porque, además de analizar los límites en el patrimonio y los servicios sobre el proceso de reproducción social, no se remite a una magnitud de ingreso sin contenido y siempre especifica su impacto asfixiante de necesidades sociales, es decir, detrás del límite del ingreso lo que se explora es el daño al valor de uso social. Lo importante, lo decisivo de la introducción del principio de la totalidad como fundamento heurístico reside en que abre un nuevo mirador: funda la conceptualización crítica de la pobreza en clave de valor de uso.

$\mathrm{Al}$ abrir este mirador Julio Boltvinik entreteje su intervención con la más rica veta del marxismo clásico. Justo

${ }^{20}$ El estudio generó seis volúmenes: en la serie Necesidades esenciales en México, vol 1: Alimentación, vol. 2: Educación, vol. 3: Vivienda, vol. 4: Salud, vol. 5: Geografía de la marginación, Coplamar, Siglo XXI, México, 1982. Y, sin número de volumen, Macroeconomía de las necesidades esenciales en México, 1983. Existió, además, un volumen directamente publicado por Coplamar, Necesidades esenciales y estructura productiva en México. Lineamientos de programación para el proyecto nacional, 1982. la plataforma que le permite edificar a la Crítica de la Economía Politica todo un nuevo horizonte de intelección con el que hace estallar la mirada del discurso del poder sobre el mundo moderno está constituida por el concepto valor de uso. Desde él es que puede descifrarse el profundo impacto que, pese a sus innegables efectos para impulsar el progreso de la técnica, la modernidad capitalista genera depredando el mundo humano de la vida. Incomprensibles resultan sus alcances si, a partir de desfigurarlo cósicamente, se reduce a una simple recolección de objetos. La depredación antiecológica generada por la técnica planetaria, la depredación destructiva producida por la red tecnológica militar y, asimismo, la depredación del proceso de reproducción social que genera la mundialización de la pobreza, todas ellas constituyen expresiones del choque de la modernidad capitalista con el mundo humano de la vida descifrables desde el valor de uso. Pensar en clave de valor de uso, entonces, es pensar en clave de afirmación vital y trascendencia humana.

Ahora bien, al momento de delimitar los alcances de esta etapa en la que Boltvinik funda el estudio de la pobreza en clave de valor de uso, más que ubicarlos en el ámbito de los problemas técnicos para efectuar el análisis simultáneo de la satisfacción de necesidades esenciales ${ }^{21}$, me parece tienen que definirse en función de que hasta aquí la adopción de una doble perspectiva (LP y NBI) para estudiar la pobreza revela que se ha inaugurado, pero apenas como esbozo, la implementación del principio de la totalidad.

Segunda etapa. El proyecto fundacional del método de medición integrada de la pobreza: la pobreza económica total y la libertad como necesidad económica.

A partir de una intensa interacción con un marxista de la India de sólida presencia en el debate económico europeo, Meghnad Desai ${ }^{22}$ — quien estaba desarrollando finos cuestionamientos a la escisión metodológica en la

\footnotetext{
${ }^{21}$ En "Satisfacción desigual de las necesidades esenciales en México" (1984), Julio Boltvinik cuestiona los problemas de medición de la pobreza que desata la adjudicación aleatoria de una carencia a las viviendas (como deterioro de sus materiales).

22 Cuya obra más relevante para el desarrollo del pensamiento crítico es Marxian Economics, 1979.
} 
medición de la pobreza en América Latina ${ }^{23}$ y en Europa, que lo llevan, junto con Anup Shah, a diseñar un nuevo método para superar esa escisión integrando todos los indicadores de medición de la pobreza24_-, Boltvinik crea el mejor método para medir la pobreza que existe hasta ahora en América: su original método de medición integrada de la pobreza (MMIP).

Un método que, sin duda, redondea la decisiva innovación que se introdujo al colocar el principio de la totalidad como fundamento heurístico porque, superando la doble perspectiva LP-NBI, unifica en una misma totalidad el conjunto global de dimensiones que determina la base material del proceso de reproducción social. Al integrar el ingreso corriente, los servicios gubernamentales, el patrimonio básico, las capacidades educativas, la propiedad de activos básicos y no básicos junto con la capacidad de endeudamiento y el tiempo libre como dimensiones de un mismo método, Boltvinik edifica una visión capacitada para explorar el impacto de la acumulación capitalista en la totalidad de necesidades del proceso de reproducción económica de la sociedad.

No es casual que, interviniendo en el debate de frontera internacional, el arribo a esta etapa lo lleve a polemizar tanto con la concepción relativa (Peter Towsend) como con la concepción absoluta (Amartya Sen) de la pobreza. Demostrando que no procede ni la reducción que relativiza las necesidades - porque esto supondría que en caso de un desastre histórico la sociedad redefine a la baja sus requerimientos y no los valores de uso con que los cubre-, ni tampoco la reducción de la pobreza a un núcleo de privación absoluta — porque ciertamente el progreso civilizatorio amplía y complejiza el sistema social de necesidades desarrollándolo y esto no puede pasarse por alto al definir la pobreza históricamente. $\mathrm{Al}$ asumir

${ }^{23}$ En Poverty, Famine and Economic Develoment. The Selected Essays of Meghnad Desai (1994a: vol. II, 205-214) se encuentra el ensayo que expone tales cuestionamientos. Ensayo que, además, muestra la profundidad de la recíproca influencia entre Boltvinik y Desai porque éste cita a aquél en importantes notas.

${ }^{24}$ Método al que, finalmente, Boltvinik ha denominado variante mejorada del Índice de Privación Vital porque hereda, pero unifica, los múltiples indicadores utilizados por Peter Townsend en su variante original del Índice de Privación. Al respecto, véase Desai y Shah, 1988. esta mirada, Boltvinik contribuye indudablemente al desarrollo del discurso crítico porque edifica un método que permite medir lo que Marx denomina la dimensión histórico-cultural o histórico-moral del proceso de reproducción social (El capital, 1981: t. 1, vol. 1, cap. 4, epígrafe 3). Esto es, la dimensión en que se manifiesta el modo concreto en que el progreso civilizatorio desarrolla el sistema medio de necesidades para cada sociedad histórica.

La innovación que se juega en esta segunda etapa va aún más lejos, ya que es justo en ella cuando de modo muy incisivo descubre la enorme importancia del tiempo libre para la conceptualización de la pobreza. A contrapelo del grueso de los economistas "estándar", que reducen la pobreza a limitación en el consumo de objetos básicos, Boltvinik demuestra que la pobreza también es pobreza de tiempo. Dicho en otros términos, que el exceso de la jornada laboral invade y reprime el tiempo libre, mutilando el proceso de reproducción de la vida porque se lesiona el desarrollo educativo, el tiempo de recuperación o, incluso, el tiempo del trabajo doméstico vitalmente necesario (trabajo que permite reconocer que los hogares lejos de ser, como cree la economía convencional, puramente unidades de consumo, son asimismo unidades de producción).

Desarrollar el principio de la totalidad para abrir el estudio de la pobreza económica total — que puede especificarse a partir de contrastar la medida de satisfacción de necesidades en referencia a la dimensión histórico-cultural de una época-y, además, descubrir al tiempo como dimensión de la pobreza —o sea, al tiempo libre como necesidad del proceso de reproducción económica social que puede ser mutilada por el exceso laboral—, en eso residen los grandes pasos adelante que se dan con el proyecto fundacional del MMIP en un libro publicado por la ONU, Pobreza y necesidades básicas (1990)25. Y que tienen en Pobreza y distribución del ingreso en México (1999) la expresión de su alto grado de sistematización, así co-

\footnotetext{
25 Dándole continuidad a su rica interacción, una vez edificado el MMIP, Boltvinik lo compara con el Índice de Privación Vital de Desai (1994b: 57-83). Poco antes elaboran, junto con Amartya Sen, un libro en el que cada uno presenta ensayos para medir no la pobreza sino el progreso social (Desai, Sen y Boltvinik, 1998 [1992]).
} 
mo la primera presentación global de resultados de estudios de la pobreza de tiempo en nuestro país.

Tercera etapa. Ampliar la mirada: el proyecto de crítica a la pobreza desde la riqueza humana total y la libertad como necesidad histórica.

A través de Antropología y marxismo (1974) de György Márkus — uno de los alumnos más importantes de Lukács ${ }^{26}$ - Boltvinik lee como nadie lo había hecho antes los Manuscritos económico-filosóficos de 1844 de Karl Marx, convirtiéndolos en la plataforma de una innovadora concepción que rompe el marco dentro del cual se había desenvuelto históricamente el debate internacional sobre la pobreza.

Llevando muy lejos la influencia que desde la segunda etapa — con la concepción histórico-materialista de las necesidades- había ejercido en él ese texto de Markus, dota al principio de la totalidad de una nueva dimensión en su historia. Mientras en la primera etapa lo instauró para pensar la pobreza en clave de valor de uso y en la segunda lo desarrolló para dar cuenta del sistema total de necesidades económicas, en esta tercera etapa lo conduce a su máximo nivel al descubrir que el gran límite en la historia del debate mundial en torno a la pobreza consiste en que, además de que el relativismo cultural de la derecha neoliberal o posmoderna siempre desconoce la medida del sistema social medio de necesidades: al trazar los umbrales de pobreza se desliza como principio una reducción esencial del ser humano a su dimensión puramente económica, es decir, se introduce un profundo error que consiste en colocar como punto de partida una destotalización o desintegramiento radical de la humanidad del ser humano. A contracorriente de esa reducción economicista, Boltvinik insiste ahora en que si y sólo si se amplía la mirada y se parte de una concepción del ser humano como totalidad — esto es, del reconocimiento de su sistema total tanto de necesidades como de capacidades económicas, políticas, culturales y psicológicas—, se puede estar en condiciones de entender los hondos im-

${ }^{26}$ Lukács es el primero en heredar —antes que la Escuela de Frankfurt- la teoría crítica de la enajenación de Marx y desarrollarla para efectuar la crítica a la modernidad capitalista del siglo XX (Lukács, 1969). pactos históricos de la pobreza tanto en el plano del estar como del ser. Ampliar la mirada, entonces, transita del sistema total de necesidades económicas al sistema total de necesidades $y$ capacidades individuales $y$ sociales como fundamento del florecimiento humano.

En este nuevo horizonte, redimensiona la concepción del tiempo libre. Éste ya no responde solamente a sus funciones para realizar la reproducción económica de la sociedad. Desbordando esa esfera (del descanso funcional a la renovación de la fuerza de trabajo, de la educación funcional a su capacitación laboral o del tiempo de trabajo doméstico vitalmente necesario), el tiempo libre adquiere toda su fuerza como plataforma histórica imprescindible para el pleno despliegue multifacético de las potencialidades humanas. En afinidad con la visión de los Grundrisse, el tiempo libre se reconoce como fundamento del desarrollo histórico de la libertad. Ampliar la mirada, así, avanza de la necesidad como libertad a la libertad como necesidad.

En síntesis, Ampliar la mirada conduce a su máximo histórico el principio de la totalidad justo porque funda el proyecto de crítica a la pobreza total desde una concepción del sujeto humano como riqueza total. Para afinar el mirador que permita llevar a cabo esa crítica, Boltvinik traza, entonces, dos ejes clave: el eje del nivel de vida y el eje del florecimiento humano. Mientras el eje del florecimiento humano corresponde al progreso histórico del sistema multidimensional o global de necesidades y capacidades humanas y, frente a él, puede reconocerse la pobreza humana total como un fragmento con el que se le recorta y desfigura; el eje del nivel de vida corresponde al sistema social medio de necesidades económicas y, frente a él, puede reconocerse la pobreza económica total como un fragmento que asfixia necesidades produciendo daño. El desarrollo del principio de la totalidad lleva así a Boltvinik al arribo de una concepción iconoclasta ya no sólo de la pobreza sino de la riqueza: partiendo de su irreductibilidad al plano del tener, la mira - justo como Marx (1982: 447) — como despliegue universal tanto de necesidades como de capacidades humanas en curso de florecimiento histórico. En consecuencia, Ampliar la mirada coloca el debate mundial sobre la pobreza en la frontera heurística más elevada de su historia. 


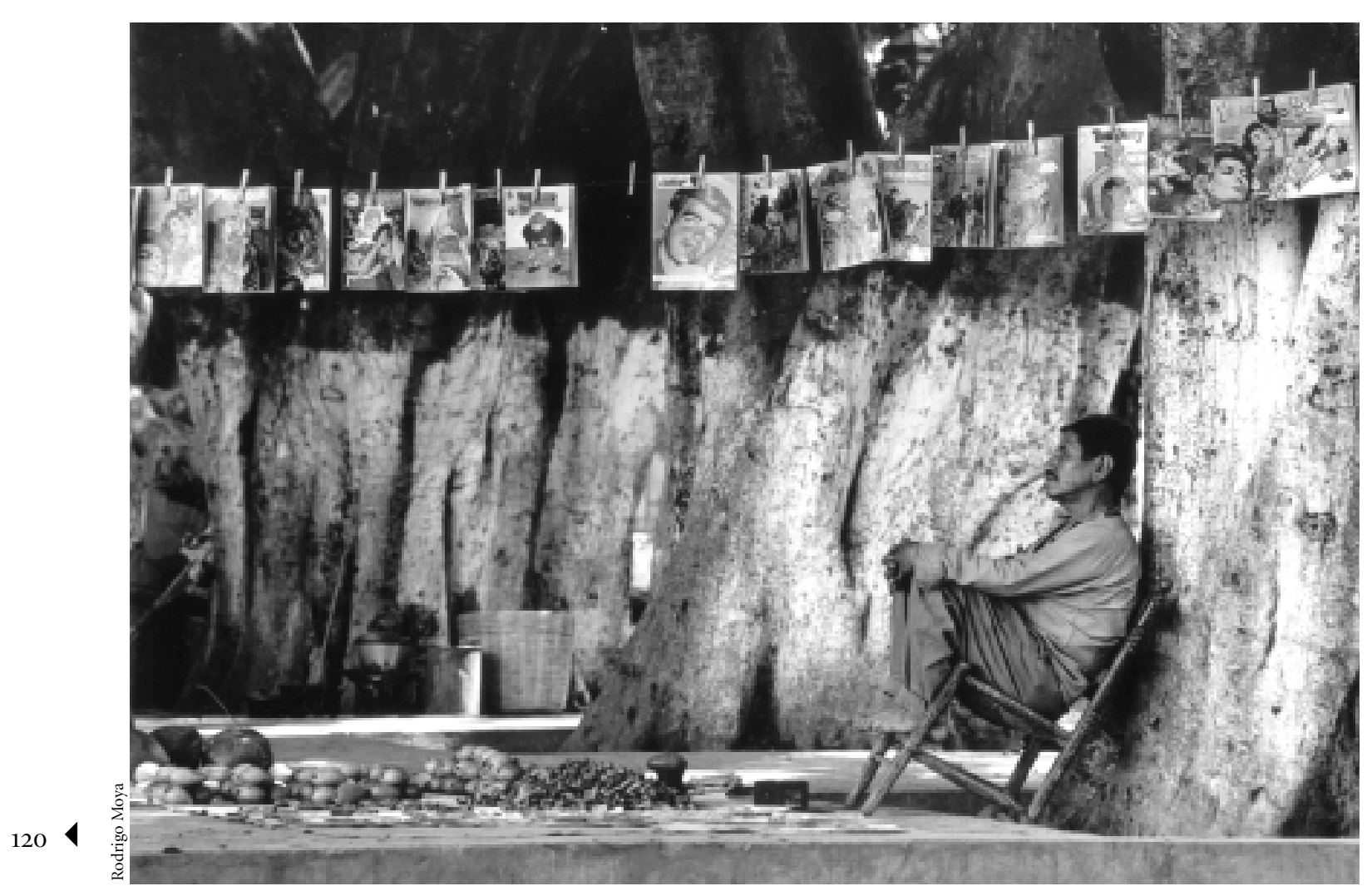

Tlalquitenango, Morelos, 1964.

\section{El principio de la transdisciplinariedad}

Un proyecto de este orden necesariamente impacta en la estructura de las ciencias sociales. No puede entablar relación con ellas desde la destotalización del sujeto. Al colocar al florecimiento humano como mirador, tiene que asumir la aventura de crear una mirada transdisciplinaria. Para el desarrollo de su conceptualización el mero tendido de puentes de intercomunicación entre las disciplinas más dispares — como economía y psicología, filosofía y estadística - es insuficiente. Imprescindiblemente tiene que embarcarse en la exploración de la trascendencia de los límites de las disciplinas sociales para aportar a la unificación del conocimiento sobre el ser humano y, desde ahí, abrir camino en la lucha contra la pobreza humana total. Porque el ser de la humanidad constituye una totalidad también tiene que constituirla su saber.
Podría decirse que el principio de la transdiciplinariedad se mueve en dos planos. Por un lado, en la edificación de los soportes del florecimiento humano como mirador; por otro, en la crítica a la reducción economicista.

Respecto del primer plano, para desplegar su aventura transdisciplinaria, Boltvinik traza un pormenorizado proyecto de diálogo con un amplio abanico de autores a los que interroga desde lo que denomina las preguntas fundacionales de este enfoque fundamentado en el florecer del género humano. Así, puede heredar sus descubrimientos, aportar para integrarlos y, asimismo, cuestionarlos. En este plano, a contrapelo de la destotalización aún preponderante en las ciencias sociales de nuestra era, demuestra creativamente que la economía requiere de la psicología y que la psicología requiere de la economía, a la vez que ambas requieren de la filosofía y la antropología y viceversa. Es imposible construir una concepción del 
ser humano como totalidad si no es desde el pensamiento transdisciplinario.

Para erigir los soportes del eje del florecimiento humano, esta aventura transdisciplinaria hereda y articula los descubrimientos que van desde la antropología filosófica de Karl Marx y György Márkus hasta la tipología del carácter - fundamentada en la economía, o sea, en el trabajo, y no en eros, aunque éste no deja de estar considerado- de Erich Fromm, incluyendo los aportes de su alumno más importante, Michael Maccoby, y, además, la teoría de la jerarquía de las necesidades de Abraham Maslow.

Respecto del segundo plano, cabe decir que despliega una puntual polémica erudita con las corrientes más importantes del debate mundial en torno a la pobreza - la economía "neoclásica", la corriente de Peter Towsend y la del Premio Nobel Amartya Sen- desde una lectura interdisciplinaria que articula la fundamentación del eje del florecimiento con la del eje del nivel de vida, integrando los aportes de la visión de las necesidades de Doyal y Gough, el desarrollo a escala humana de Max Neef et al. y la dialéctica producción/consumo como fundamento del progreso histórico en Terrail.

Esta fundamentación transdisciplinaria le permite a Boltvinik ver que, ciertamente, las corrientes más relevantes del debate mundial sobre la pobreza se encuentran en un profundo entrampamiento por su reducción economicista del ser humano. No sólo la economía "neoclásica” de la nueva derecha neoliberal o posmoderna que introduce una plataforma giratoria simulando colocar como fundamento la utilidad cuando, más bien, sustituyéndola, pone como punto de partida una línea de ingreso sin referencia al valor de uso. Lo que lleva a un círculo tautológico que pretende "explicar" la pobreza de ingreso por la pobreza de ingreso. Además de ella, incluso ni la mirada multidisciplinaria de Towsend ni tampoco el enfoque de las "capabilities" y "functionings" de Sen, que parecían abrir brecha hacia una ampliación en la concepción del ser humano, superan la reducción economicista. Mientras Towsend cae en una doble reducción - unidimensionalizando la visión de la pobreza al método LP y, luego, al nivel de vida—, Sen, en verdad, no ha ampliado la mirada desde las necesidades hacia las capacidades y la libertad porque sus "capabilities" simplemente son "oportunidades abiertas por el ingreso" y sus "functionings" no responden al tiempo libre sino a la posibilidad de elegir entre diversos estados deseables de consumo.

El pensamiento transdiciplinario constituye, así, un principio decisivo de la crítica a la pobreza humana total desde la riqueza humana total.

\section{El principio de la economía moral}

Negándose desde el inicio de sus intervenciones en el debate internacional sobre pobreza a aceptar el inhumanismo que se esconde detrás de formulaciones como la de que las ciencias sociales y, ante todo, la ciencia económica, para ser tales tienen que ser "objetivas" o "puras", en el sentido de apolíticas o amorales, Boltvinik, colocándose en una sólida posición epistemológica crítica de la escisión sujeto-objeto, insiste en que no hay modo de asumir una postura sobre el objeto en el mundo sin asumir una postura sobre el sujeto ${ }^{27}$.

Impresionado en la Universidad East Anglia, desde 1996, cuando - como profesor visitante- conoce el horizonte de intelección de la economía moral —que lo lleva a titular con ese nombre su columna periodística semanal-, comparte con ella el profundo rechazo a la dicotomía hechos/valores que tanto ha permeado desde el positivismo lógico al pensamiento económico desde hace un siglo.

Fundado por E. P. Thompson —el gran historiador británico sobre el cual alguien como Eric Hobsbawn se expresó afirmando que había que llamarlo "simplemente un genio"- para cuestionar la inmoralidad de lucrar con las necesidades de la gente, el horizonte de la economía moral lleva la discusión económica e histórica a una si-

\footnotetext{
${ }^{27}$ Como afirmaba Marcuse, incluso en el campo epistemológico la existencia del objeto al margen del sujeto es sencillamente imposible, justo porque el objeto socialmente producido es la objetivación del objetivo elegido por el sujeto productor, la relación sujeto-objeto constituye una unidad indisoluble. En alemán este fundamento se percibe, apunta de fondo Marcuse, ya que, el significado del concepto de "objeto" es "lo-otro-que-sí-mismo" (Marcuse, 1969: 19).
} 
tuación límite - la pobreza que pone en peligro la reproducción de multitudes - para revelar que sencillamente es imposible producir conceptos sin emitir a la vez juicios de valor.

Convirtiendo el concepto de dimensión históricomoral o histórico-cultural de Karl Marx en plataforma de toda una concepción de la historia económica, con la economía moral —que nació para explicar los estallidos políticos de fines del siglo XVIII de los trabajadores ingleses cuando el capitalismo naciente minaba su acceso al cereal histórico de la civilización europea, el trigo (en forma de pan)28_, E. P. Thompson pone al descubierto que el valor de uso que rige el proceso de reproducción social de una época, esto es, el bien económico, constituye un fundamento con el que siempre se correlaciona la noción social del Bien moral que se erige en ella. Cuando se piensa en clave de valor o de la forma dinero para acumularlo como capital, las necesidades concretas de la sociedad se tornan irreconocibles; en cambio, cuando se piensa en clave de valor de uso el sistema histórico-social de necesidades se sitúa en el centro del observatorio.

Por eso, pensar en clave de valor de uso exige pensar inmediatamente en clave normativa.

Llevando esta incisiva formulación del plano de la historia económica al plano de la epistemología, en Ampliar la mirada Boltvinik integra a la edificación del florecimiento humano como mirador la recuperación de la crítica enderezada por un filósofo de la ciencia de la altura de Hilary Putnam al positivismo lógico para demoler la nociva dicotomía hechos/valores que tanto restringe el desarrollo del pensamiento económico en nuestro tiempo.

Si existe una época en la que, a todas luces, la formulación del "objetivismo puro" o "neutro" revela su com-

28 Proyectando cómo la dimensión histórico-moral siempre se refiere al sistema social medio de necesidades de una sociedad y cómo choca con el dominio que sobre él ejerce la modernidad capitalista, en su ensayo fundacional de la economía moral, Thompson dice: "Es posible detectar en casi toda acción de masas del siglo XVIII alguna noción legitimadora [...]. Los hombres y las mujeres que constituían la multitud [en sus revueltas por el pan] creían estar defendiendo derechos o costumbres tradicionales y, en general, que estaban apoyados por el amplio consenso de la comunidad" (Thompson, 2002: 365). plicidad con el poder moderno es ésta en la que ante la mundialización de la pobreza el cinismo histórico intenta recubrirse con aquél. En este sentido, Ampliar la mira$d a$ asume la economía moral como principio conceptual/ético buscando impulsar el desarrollo de un mirador histórico comprometido con el bienestar y el florecimiento del género humano.

\section{El principio de la soberanía}

Reivindicar el contenido histórico-moral de una sociedad histórica, esto es, el derecho de toda la nación a satisfacer el sistema social medio de necesidades que ha desarrollado en una época determinada — que es justo lo que se hace desde el MMIP al reconocer multidimensionalmente las necesidades que requieren ser cubiertas para superar la pobreza económica total—y, más aún, plantear el proyecto de trascendencia histórica de la pobreza humana total con el objetivo de estimular el florecimiento individual y social exige que Boltvinik, avanzando mucho más allá del campo político al que regularmente se circunscribe la lucha contra la pobreza, insista en que, lejos de bastar un mero giro, así fuera drástico, en la política social, la condición histórica estratégica para asumir esas necesidades reside, precisamente, en recuperar la autodeterminación nacional.

No podría entenderse el alcance de su propuesta de acción si por ella se comprendiera un simple regreso al pasado, esto es, al Estado nacionalista liberal y keynesiano.

Buscando contrarrestar las relaciones de poder centroperiferia que se juegan en el siglo XXI, en un ensayo decisivo para tornar explícitos planteamientos estratégicos derivados de Ampliar la mirada, formula la necesidad histórica de articular el proyecto de la autodeterminación nacional con la generación de masas críticas mínimas tanto de capacidades tecnológicas como de capacidades sociales (Boltvinik, 2006b).

Cuando la autogestión —observa atinadamente- de modo anti-imperialista y hasta anti-capitalista se instala, pero en "condiciones de aguda escasez de recursos", la autodeterminación encara límites objetivos infranqueables que le bloquean avanzar. 
Para modificar la dinámica histórico-económica y política de un país, que es el reto que exige encarar la lucha por la trascendencia de la pobreza económica y humana total, es imprescindible un movimiento antisistémico que haga valer la autodeterminación nacional, pero, asimismo, es indispensable asumir la producción del desarrollo de una red tecnológica nacional y de un sistema educativo que capacite grandes masas de jóvenes altamente calificados para mantener el progreso económico e instrumental continuamente en curso. Una estrategia de este orden podría dotar a la nación de una plataforma adecuada para enfrentar y redefinir su lugar en el rapport de forces de la mundialización actual.

Para responder a la edificación de condiciones para el florecimiento humano, la autodeterminación nacional no podría remitirse a los marcos de acción de una estrategia capitalista nacionalista, tendría que redimensionar transcapitalistamente el ejercicio de la soberanía del Estado nacional para convertirlo en un medio estratégico muy superior a la mera redistribución del ingreso, esto es, funcional al desarrollo de una desmercantilización social históricamente creciente. Es decir, de una reconfiguración del proceso de reproducción social que, con base en un movimiento nacional soberano, arrebate al Estado el reconocimiento de múltiples necesidades sociales que tendrían que ser cubiertas mediante servicios públicos sin cosificación del sujeto social ni venta de la fuerza de trabajo en el mercado laboral.

En este punto se proyecta una esencial coincidencia estratégica entre Boltvinik y Wallerstein, quien, en un ensayo en el que realiza un balance de las condiciones para un posible reposicionamiento de los Estados periféricos, afirma:

En la media duración, lo mejor que pueden hacer los movimientos es presionar por la desmercantificación dondequiera que puedan y en la medida en que puedan [...] La desmercantificación no sólo hace frente a las tendencias del neoliberalismo, edifica las bases de una cultura política alternativa. Por supuesto, los teóricos del capitalismo se han burlado mucho tiempo de la desmercantificación argumentando que es ilusoria [...], que lo único que hace es garantizar la falta de crecimiento económico y, por consiguiente, la pobreza. Todo esto es falso. Sólo tenemos que mirar las dos instituciones mayores del mundo moderno - las uni- versidades y los hospitales - para darnos cuenta de que, por lo menos hasta hace veinte años, nadie cuestionó que deberían perdurar como instituciones no lucrativas, sin accionistas ni especuladores [...] El problema [...] reside en la construcción de las bases sobre las que crearemos el sistema-mundo sucesor (2006: 14-15).

En consecuencia - y me parece que esta es la formulación estratégica tácita pero decisiva que deriva de Ampliar la mirada-, entre la soberanía nacional y la soberanía del Estado tendría que desarrollarse una rica dialéctica transcapitalista de doble sentido: por un lado, el desarrollo de un sólido movimiento nacionalista tendría que ser el fundamento de la conformación de un Estado soberano; por otro, en tanto resultado y, asimismo, presionado por la soberanía del movimiento nacional, ese Estado tendría que asumir las condiciones para el desarrollo de la soberanía humana: sin duda, la base epocal del florecer del género humano.

\section{Bibliografía}

Amery, Carl, 1998, Auschwitz, ¿comienza el siglo XXI?, Fondo de Cultura Económica, Madrid.

Amin, Samir, 2003, "Pobreza mundial, pauperización y acumulación de capital", Espai Marx, revista electrónica, España.

Arizmendi, Luis, 2003a, "La globalización como mito y simulacro histórico. Primera parte", eseconomía, núm. 2, ESE, Instituto Nacional Politécnico, México.

_ 2003b, "La globalización como mito y simulacro histórico. Segunda parte", eseconomía, núm. 3, ESE, Instituto Nacional Politécnico, México

_ 2006, "La crisis ambiental mundializada en el siglo XXI y sus disyuntivas", Mundo Siglo XXI, núm. 3, Centro de Investigaciones Económicas, Administrativas y Sociales, Instituto Politécnico Nacional, México.

Arrighi, Giovanni y Beverly Silver, 2005, "Trabajadores del Norte y del Sur”, eseconomía, núm. 5, trad. de Luis Arizmendi, ESE, Instituto Politécnico Nacional, México.

Banco Mundial, 2002, Globalization, Growth and Poverty. Building an Inclusive World Economy, Oxford University Press, Washington. [Globalización, crecimiento y pobreza. Construyendo una economía mundial incluyente, $\mathrm{Al}-$ faomega, Colombia, 2002].

Boltvinik Julio, 1984, "Satisfacción desigual de las necesidades esenciales en México", en La desigualdad en México, Siglo XXI, México. 
1986, "Modo de producción estatal y satisfacción de necesidades esenciales en México”, Investigación Económica, vol. XLV, núm. 177, julio-septiembre, UNAM, México.

—_, 1990, Pobreza y necesidades básicas, PNUD, Caracas.

, 1999, Pobreza y distribución del ingreso en México, Siglo XXI, México.

_ 2006a, "El rechazo al concepto de necesidades humanas”, Mundo Siglo XXI, núm. 3, Centro de Investigaciones Económicas, Administrativas y Sociales, Instituto Politécnico Nacional, México.

_, 2006 b, "Recuperar la autodeterminación nacional", La Jornada, 24 de marzo.

Coplamar, 1982, Necesidades esenciales y estructura productiva en México. Lineamientos de programación para el proyecto nacional, Coplamar, México.

__ 1983, Macroeconomía de las necesidades esenciales en México, Coplamar, Siglo XXI, México.

Chomsky, Noam, 2003, Chomsky. Obra esencial, Crítica, Barcelona.

Chossudovsky, 2002, Globalización de la pobreza y nuevo orden mundial, Siglo XXI, México.

CIA, 2000, Global Trends 2015: A Dialogue About The Future With Nongovernment Experts, NIC, Washington.

Desia, Meghnad, 1979, Marxian Economics, Littlefield, Adams \& Co., Totowa, New Jersey.

_- 1994a, Poverty, Famine and Economic Development. The Select Essays of Meghnad Desai, vol. II, Edward Elgar Publishing Co., Vermont. —, 1994b, "Poverty Measurements and Alternatives Indicators of Development", en Rolph van der Hoeven y Richard Anker, Poverty Monitoring. An international Concern, Mc Millan, St. Martins Press, Londres.

_ - y Anup Shah, 1988, "An Econometric Approach to the Measurement of Poverty", Oxford Economics Papers, núm. 40, Oxford.

__, Amartya Sen y Julio Boltvinik, 1998 [1992], Indice de progreso social. Una propuesta, UNAM, México [ed. original, PNUD, Bogotá].

Echeverría, Bolívar, 1995, Las ilusiones de la modernidad, El Equilibrista, UNAM, México.

__ 1998, "Violencia y modernidad", en Valor de uso y utopía, Siglo XXI, México.

FMI, 2006, World Economic Outlook, Washington.

Galbraith, John Kenneth, 1979, The Nature of Mass Poverty, Harvard University Press, Cambridge.

Gordon, David, 2004, "Construyendo una estrategia para combatir la pobreza”, en Julio Boltvinik y Araceli Damián (coords.), La pobreza en México y el mundo, Siglo XXI, México.

Harris, Nigel, 1987, The End of the Third World, Harmondsworth, Middx, Penguin, Reino Unido.
Hewlett, Sylvia Ann, 1993, Child Neglect in Rich Nations, UNICEF, Nueva York.

Horkheimer, Max, 2006, Estado autoritario, Ítaca, México.

Kébabdjian, Gérard, 2006, “Globalización: ¿Debilitamiento o reconfiguración de los Estados del Norte?”, Mundo Siglo XXI, núm. 6, Centro de Investigaciones Económicas, Administrativas y Sociales, Instituto Politécnico Nacional, México.

Khan, Mohsin, 1990, "The Macroeconomic Effects of Fund Supported Adjustement Programs”, IMF Staff Papers, vol. 37, núm. 2.

Lukács, György, 1969, Historia y conciencia de clase: estudios de dialéctica marxista, Grijalbo, México.

Marcuse, Herbert, 1969, Ética de la revolución, Taurus, España.

Márkus, György, 1974, Antropología y marxismo, Grijlabo, Barcelona.

Marx, Karl, 1981, El capital, Siglo XXI, México.

— 1982, Grundrisse, t. I, Siglo XXI, México.

PNUD, 1999, Human Development Report 1999, Globalization with a Human Face, Oxford University Press, Reino Unido.

Sloterdijk, Peter, 2003, Crítica de la razón cínica, Siruela, Madrid.

Soros, George, 1999, La crisis del capitalismo global. La sociedad abierta en peligro, Plaza y Janés, Madrid.

Stiglitz, Joseph, 1998, More Instruments and Broader Goals: Moving Towars a Post-Washington Consensus, Wider Annual Lecture 2, University World Institute for Development Economics Research (WIDER), Finlandia.

— 2002, El malestar en la globalización, Taurus, Madrid.

Thompson, Edgard Palmer, 2002, "La economía moral de la multitud en la Inglaterra del siglo XVIII" en Thompson. Obra esencial, Crítica, Barcelona.

Townsend, Meter, 2004, "La medición internacional de la pobreza y las políticas para combatirlas", en Julio Boltvinik y Araceli Damián (coords.), La pobreza en México y el mundo, Siglo XXI, México.

Toye, John, 2004, "Nacionalizar la agenda contra la pobreza”, en Julio Boltvinik y Araceli Damián (coords.), La pobreza en México y el mundo, Siglo XXI, México.

Tritch, Teresa, 2006, "The Rise of the Super-Rich", The New York Times, 19 de junio.

Wallerstein, Immanuel, 1996, "El colapso del liberalismo" en Después del liberalismo, Siglo XXI, México.

_ 2001, "Las ciencias sociales y el interludio comunista" en Conocer el mundo. Saber el mundo, Siglo XXI, México.

_ 2006, “Después del desarrollo y la globalización, ¿qué?”, Mundo Siglo XXI, núm. 3, trad. de Luis Arizmendi, Centro de Investigaciones Económicas, Administrativas y Sociales, Instituto Politécnico Nacional, México.

Varios autores, 1999, Geopolítica del hambre, Icaria, Madrid. 